\title{
Political Neuroscience: The Beginning of a Beautiful Friendship
}

\author{
John T. Jost \\ New York University \\ Department of Psychology \\ H. Hannah Nam \\ New York University \\ Department of Psychology \\ David M. Amodio \\ New York University \\ Department of Psychology \\ Jay J. Van Bavel \\ New York University \\ Department of Psychology
}

The emergence of political neuroscience-an interdisciplinary venture involving political science, psychology, and cognitive neuroscience-has piqued the interests of scholars as well as the mass public. In this chapter, we review evidence pertaining to four areas of inquiry that have generated most of the research in political neuroscience to date: (1) racial prejudice and intergroup relations; (2) the existence of partisan bias and motivated political cognition; (3) the nature of left-right differences in political orientation; and (4) the dimensional structure of political attitudes. Although these topics are well-known to political psychologists, the application of models and methods from neuroscience has renewed interest in each of them and yielded novel insights. There is reason to believe that many other areas of political psychology await similarly promising renewals and that innovative methods will continue to advance our understanding of the physiological processes involved in political cognition, evaluation, judgment, and behavior. We address limitations, criticisms, and potential pitfalls of existing work-including the "chicken-and-egg problem"-and propose an ambitious agenda for the next generation of research in political neuroscience.

KEY WORDS: political neuroscience, racial prejudice, partisanship, ideology

"It is evident that the state is a creation of nature, and that man is by nature a political animal."

-Aristotle

One of the most trenchant social and political psychologists of the twentieth century, William J. McGuire (1993), observed that the "politics and psychology relationship has been lively and 
long-lasting as interdisciplinary affairs go, its longevity fostered by frequent shiftings of its popular topics, methods, and theories" (p. 363; see also Jost \& Hardin, 2011). As in all sustainable relationships, psychology and political science have, for the most part, changed together rather than grown apart (e.g., see Huddy, Sears, \& Levy, 2013; McGuire, 1993; Sears, Huddy, \& Jervis, 2003). Perhaps it was inevitable, then, that political scientists would come to share psychologists' enthusiasm for the models and methods of neuroscience, including the use of electroencephalography (EEG), magnetic resonance imaging (MRI), and other measures of the central and peripheral nervous system (e.g., Alford \& Hibbing, 2008; Amodio, Jost, Master, \& Yee, 2007; Carmen, 2007; Fowler \& Schreiber, 2008; Schreiber et al., 2013; Smith, Oxley, Hibbing, Alford, \& Hibbing, 2011b; Taber \& Young, 2013; Theodoridis \& Nelson, 2012).

Political neuroscience is an interdisciplinary venture that tackles questions of mutual interest to political scientists and psychologists by drawing, at least in part, on the theories, methods, and assumptions of biology, especially neuroscience. The application of neuroscience to political topics offers a powerful set of research methods that promises to integrate multiple levels of analysis. As E. O. Wilson (1998) wrote in Consilience: The Unity of Knowledge: "the social sciences are intrinsically compatible with the natural sciences. The two great branches of learning will benefit to the extent that their modes of causal explanation are made consistent" (p. 205). Through techniques such as neuroscience and behavioral genetics, it may be possible to analyze complex phenomena in terms of underlying constituent mechanisms and processes (see also Cacioppo \& Berntson, 1992).

Budding enthusiasm for the use of neuroscientific methods to examine questions at the intersection of psychology and politics was obvious enough that several commentators predicted the emergence of political neuroscience (Cacioppo \& Visser, 2003; Lieberman, Schreiber, \& Ochsner, 2003; Marcus, 2003) — three years before the first bona fide empirical publications actually appeared (Knutson, Wood, Spampinato, \& Grafman, 2006; Westen, Blagov, Harenski, Kilts, \& Hamann, 2006). Cacioppo and Visser (2003) noted that "neuroscientists and political psychologists [were] not strange bedfellows," nor were they "comrades in arms" (p. 647) and-consistent with Wilson's (1998) views about consilience-anticipated that neuroscientific contributions would "build on rather than substitute for the extant theory and methods in political psychology" (p. 655). To date, a genuinely collaborative stance between political psychology and neuroscience has been maintained in theoretical and empirical work. As a result, the coming together of politics and neuroscience has been fruitful and mutually beneficial-both contributing to established theories in social and political psychology (Jost \& Amodio, 2012) and inspiring brand new theoretical perspectives (Hibbing, Smith, \& Alford, in press). As Taber and Young (2013) pointed out, the field is experiencing "an exciting turning point" in which researchers are "looking inside the black box already" (p. 549).

The use of neuroscientific methods to examine questions of political psychology brings with it clear advantages in terms of technical sophistication and relatively precise, objective measurements that are less subject to social desirability and self-presentational biases, in comparison with research that depends upon methods of self-report (such as public opinion surveys). Different techniques, it should be noted, have their own strengths and weaknesses, and so some methods are better suited for certain theoretical purposes than others. So far, fMRI is one of the most commonly used techniques in political neuroscience. It has high spatial resolution and is therefore well-equipped to represent neural activity in distinct brain regions: It is useful for addressing questions of the form where in the brain is $X$ process instantiated? At the same time, the temporal resolution of fMRI is low, making it far from ideal for answering questions about the timing and sequence of processing stages (see also Theodoridis \& Nelson, 2012). Furthermore, the equipment is extraordinarily bulky and expensive, and participants are required to immobilize themselves in a loud, claustrophobic environment while their brains are scanned. For many scientific purposes, EEG provides a much less expensive and more convenient option that brings high temporal resolution (but low spatial resolution), making it especially useful for measuring the time course of a given psychological process. 
Our enthusiasm about the promise of political neuroscience should not be taken as Pollyannaish when it comes to the (indiscriminate) use of neuroscientific methods to tackle complex questions about social and political behavior. Cognitive neuroscientists are quick to acknowledge that there are limits to what can be inferred about the mental states and processes of individual actors solely on the basis of brain activity and anatomical structure (e.g., Cacioppo et al., 2003; Poldrack, 2006; Thomas \& Baker, 2012), and political neuroscientists, too, are advised to proceed with caution (Jost \& Amodio, 2012; Theodoridis \& Nelson, 2012). Our review of the literature reveals that most studies thus far have concentrated simply on "brain mapping," that is, seeking to identify correlations between neural functions (or region-specific activation) and political attitudes and behaviors. This is a necessary step in the research process, but it is also important to bear in mind problems associated with the drawing of "reverse inferences," that is, concluding that because a given brain region (e.g., the amygdala) is generally involved in a certain type of task or function (e.g., the processing of emotionally salient information) that its activation in a given instance must indicate the presence of a specific mental process (e.g., the experience of emotion). As Poldrack (2008) has pointed out, the method of reverse inference provides only weak evidence concerning the operation of specific mental processes "because of the fact that activation is rarely selective," insofar as "regions are often activated by a wide range of mental tasks" (p. 224). The subfield of political neuroscience will have truly come of age when the knowledge gained from brain-mapping studies is parlayed successfully into hypothesis-driven tests of behavioral as well as neurological outcomes specified by processoriented theories in political psychology (see also Amodio, 2010a). Steps have indeed been taken in this direction, as our review will show, but it is worth emphasizing that these are still early days for political neuroscience - the "beginning of a beautiful friendship," so to speak.

In the remainder of this article, we review four areas of empirical inquiry that account for most of the publicly available research in political neuroscience: (1) racial prejudice and intergroup relations; (2) the existence of partisan bias and motivated political cognition; (3) the nature of left-right differences in political orientation; and (4) the dimensional structure of political attitudes. All of these topics are well-known to political psychologists (e.g., Feldman, 2013; Huddy et al., 2013; Jost \& Sidanius, 2004; McGuire, 1985, 1993; Sears et al., 2003; Taber \& Lodge, 2006; Tetlock, 2007) — and yet the application of neuroscientific methods has breathed new life into each of them. We have little doubt that many other research areas await similarly promising renewals. Because the alliance between politics and neuroscience is so new, our review can afford to be brief and forward-looking but also reasonably comprehensive.

\section{Racial Prejudice and Intergroup Relations}

From the earliest days of American slavery through the Civil Rights era and beyond, racial themes have frequently dominated the political landscape. Thus, it is no surprise that the study of both subtle and blatant forms of racial prejudice (and their implications for intergroup relations as well as electoral politics) constitutes a major area of political psychology (e.g., Mendelberg, 2001; Sears et al., 2003; Valentino, Hutchings, \& White, 2002). Of particular interest is the question of whether racial resentment (of one kind or another) continues to influence social and political outcomes (see Sears, Sidanius, \& Bobo, 2000). There is by now a well-developed research literature on the neural processes involved in racial categorization and prejudice, as well as intergroup relations in general. Because of increased professional specialization and the thickness of disciplinary boundaries, advances in social cognitive neuroscience have been slow to reach political psychology. In an effort to expedite the transfer of knowledge, we recount the history of research on physiological indicators of racial attitudes before turning to some of the more recent breakthroughs afforded by neuroscience methods. Prejudice-related research in social and cognitive neuroscience, which preceded neuroscientific studies of explicitly political cognition and behavior by five or six years, 
provides a solid foundation for many of the ideas and techniques that are now being applied to other questions about society and politics, and it clearly demonstrates the promise that neuroscience holds for political psychology.

Some of the very earliest psychophysiological explorations of social behavior, which were conducted in the 1950s, focused on White Americans' responses to reminders of racial differences. In these studies, researchers used nonverbal methods to assess Whites' emotional responses while they were exposed to Black interaction partners or to statements invoking racial or other political views that deviated from those held by the participants (for a review, see Guglielmi, 1999). In one series of studies, for instance, highly prejudiced Whites who heard Blacks described in a favorable light exhibited increased physiological arousal (Cooper \& Siegel, 1956; Cooper \& Singer, 1956), which was assessed in terms of the skin conductance response (SCR) - sweat gland activity (i.e., the sweating of palms) that is associated with activity of the sympathetic nervous system (see Bradley, Cuthbert, \& Lang, 1990). The authors argued, on the basis of these results, that prejudiced attitudes were "emotionally fortified" - that is, deeply ingrained in affective processes-and that exposure to contradictory opinions about racial out-groups created emotional conflict. In another study, participants completed a bogus experimental task in which two different experimenters-one White and one Black-entered the participant chamber at different times, ostensibly to check the electrode connections on the participant's hand (Rankin \& Campbell, 1955). In fact, this was a ruse that allowed the experimenters to interact with and even touch the wrist of the participants while skin conductance was recorded. Although White participants reported that they liked the White and Black experimenters equally well, they exhibited larger SCRs when interacting with the Black experimenter. This was one of the first studies to suggest a possible dissociation between verbal and nonverbal reactions to racial stimuli, raising the prospects that participants were either concealing or unaware of their prejudices (cf. Devine, 1989). Because of the groundbreaking work of that era (see also Allport, 1954), subsequent generations of researchers have made great strides in understanding physiological and other nonverbal manifestations of intergroup bias and its consequences (e.g., Dovidio, Hebl, Richeson, \& Shelton, 2006). Methodological innovations in neuroscience have proven especially useful in this general endeavor (for reviews, see Amodio, 2008; Cunningham \& Van Bavel, 2009; Derks, Scheepers, \& Ellemers, 2013; Ito \& Bartholow, 2009; Kubota, Banaji, \& Phelps, 2012).

\section{Neural Basis of Prejudice and Stereotyping}

Current investigations focus on the neural correlates of intergroup social cognition, especially when it comes to implicit (as compared with explicit) processes involved in stereotyping and prejudice. This ground was first settled in pioneering studies by Hart et al. (2000) and Phelps et al. (2000), both of which used functional MRI (fMRI) to measure White participants' brain activity while they viewed faces of Whites and Blacks. The goal of these studies was to determine whether the amygdala - an almond-shaped structure located bilaterally in the medial temporal lobes that plays an important role in classical fear conditioning (Davis, 1992; Fendt \& Fanselow, 1999; LeDoux, 1996; see Figure 1a)—is involved in implicit racial bias. Neither study revealed an overall difference in amygdala activity as a function of exposure to own-race versus other-race faces, but this null result may be attributable to a methodological constraint (the fact that White and Black faces were presented in separate blocks of trials). More importantly, Hart and colleagues (2000) observed that amygdala activity was slower to habituate to own-race than other-race faces, and Phelps and colleagues (2000) discovered that amygdala activation following exposure to Black (vs. White) faces was correlated with individual differences in implicit racial bias. (In Table 1, we have listed and described brain structures and functions that have been found to correlate with social and political behavior in the studies reviewed in this chapter). 
(a)

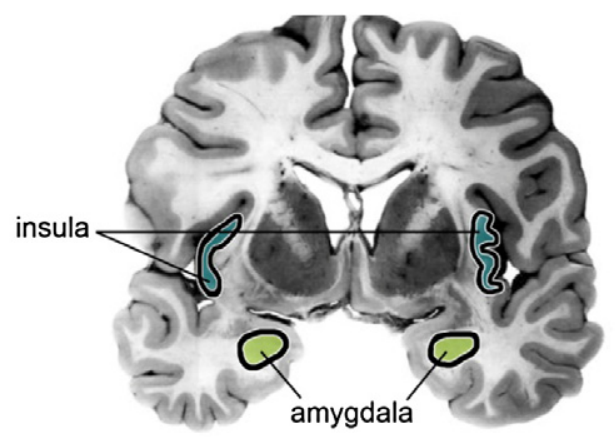

(b)

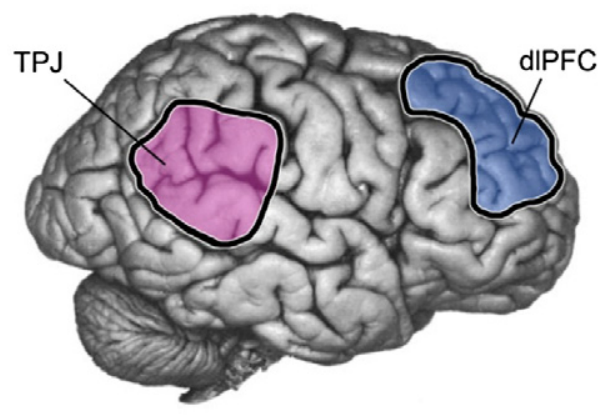

(c)

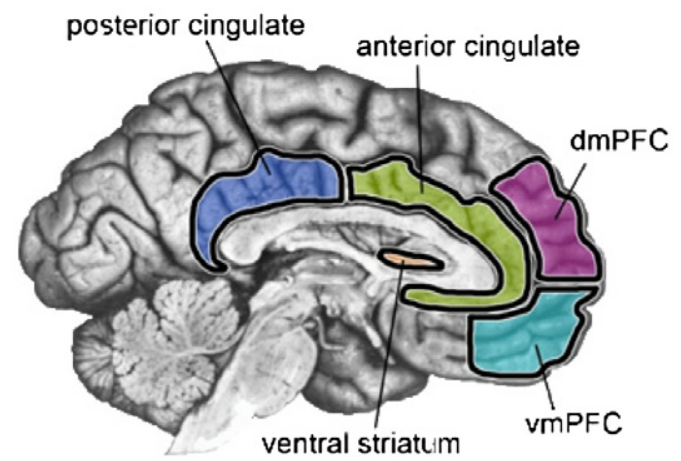

Figure 1. Brain regions and structures that are most commonly observed in studies of political neuroscience: Views of (a) coronal, (b) sagittal, and (c) midsagittal planes.

Amodio, Harmon-Jones, and Devine (2003) considered the theoretical implications of conceiving of the amygdala as a neural substrate of implicit racial bias and focused on the startle eyeblink response - a physiological index of amygdala activity - in response to the presentation of faces of White and Black people. The startle eyeblink method has been used (1) to index the specific subregion of the amygdala that is associated with the expression of fear and (2) to measure changes in amygdala activity within milliseconds after a stimulus is presented, thereby tapping into processes that operate rapidly (Davis, 2006; Lang, Bradley, \& Cuthbert, 1990). Using this approach, Amodio and colleagues (2003) observed a significant increase in amygdala activity immediately following exposure to Black (vs. White) faces, thereby linking implicit racial responses to a neural mechanism of fear processing. This pattern — of greater amygdala activity in Whites' responses to Black than White faces-has now been replicated in several fMRI studies (e.g., Cunningham et al., 2004; Krendl, Macrae, Kelley, Fugelsang, \& Heatherton, 2006; Lieberman, Hariri, Jarcho, Eisenberger, \& Bookheimer, 2005; Ronquillo et al., 2007; Wheeler \& Fiske, 2005), and it has also provided a basis for subsequent explorations of partisan bias in explicitly political contexts, which we review in the next section.

The broader goal of the research program initiated by Amodio et al. (2003) was to illuminate the psychological mechanisms underlying implicit racial bias, with an eye toward the incorporation of insights from neuroscience that could be applied fruitfully to the study of intergroup bias. For 


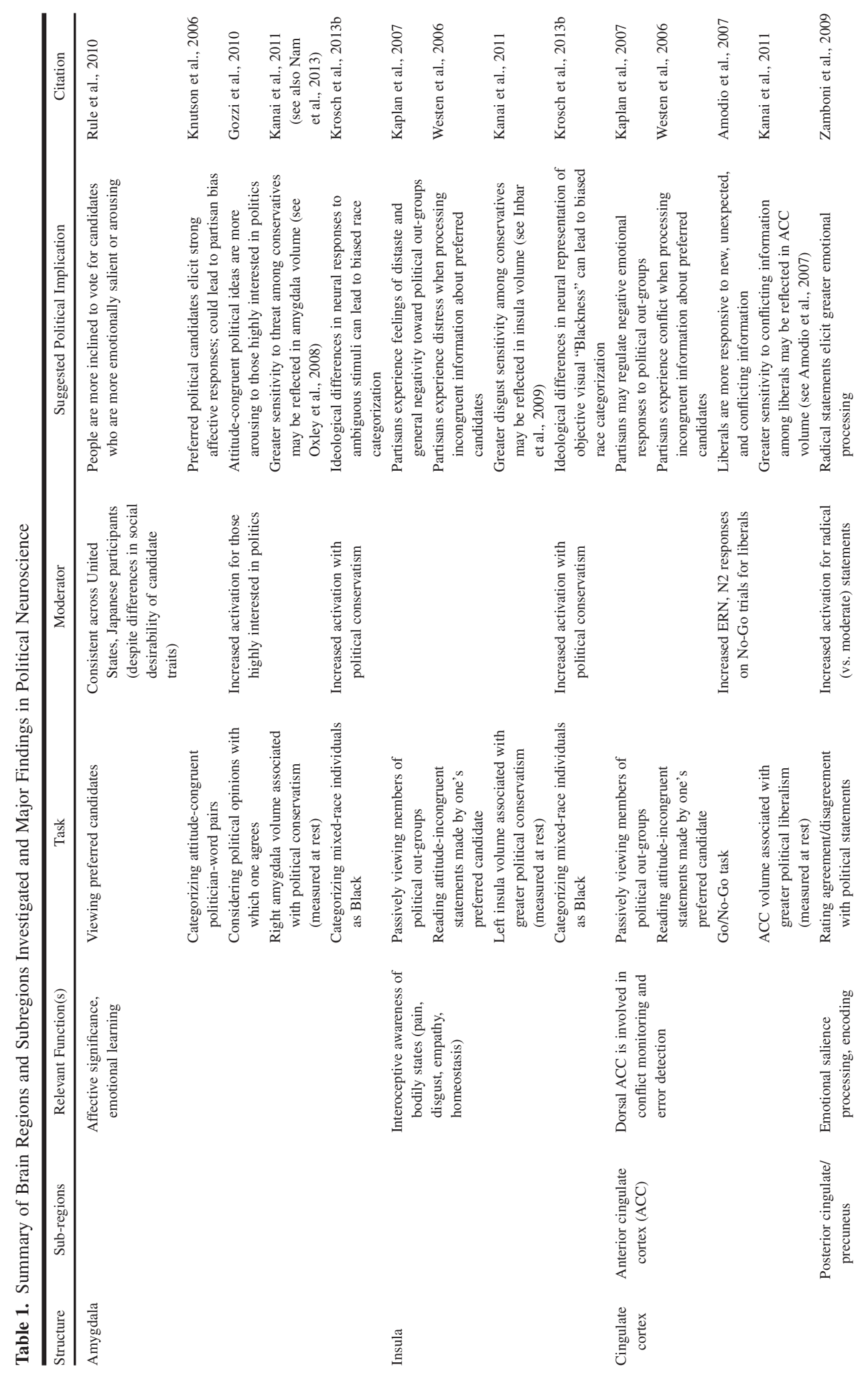




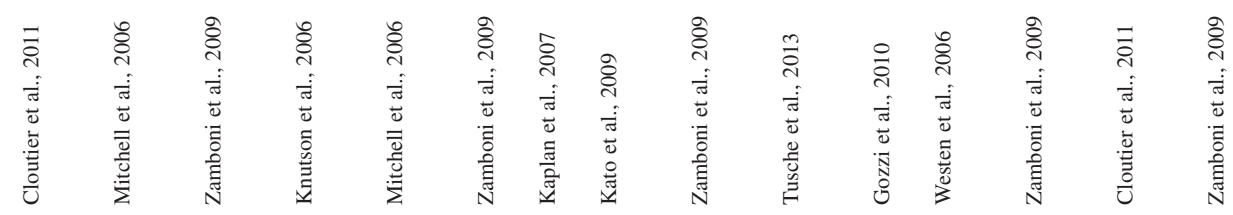
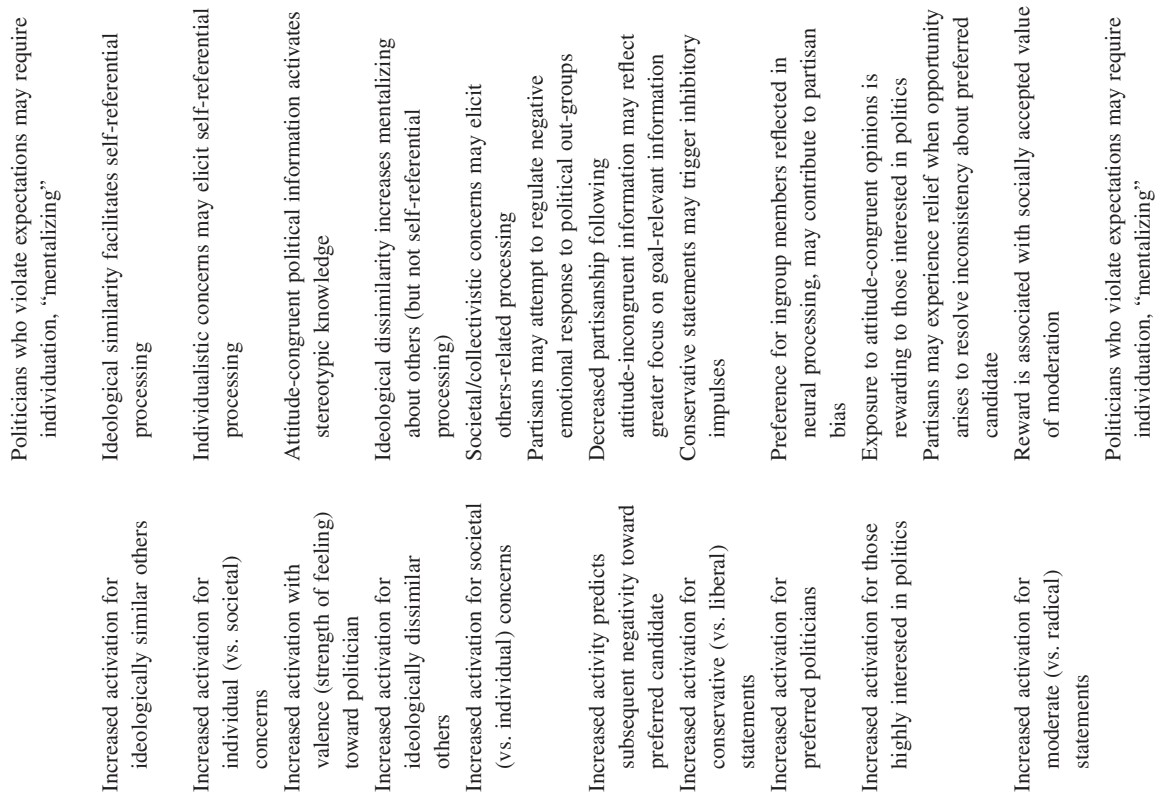

$\frac{2}{5}$

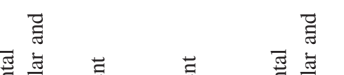
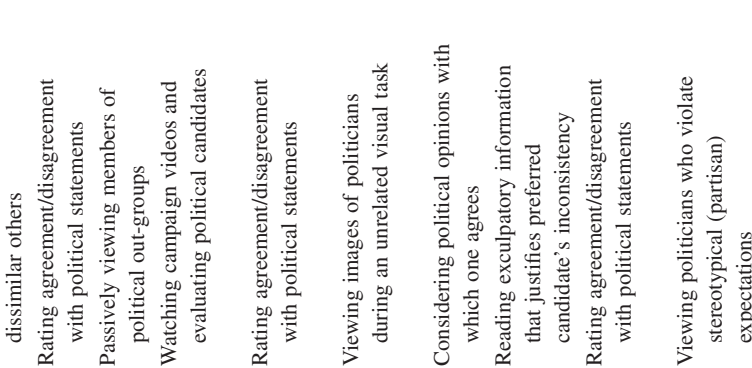

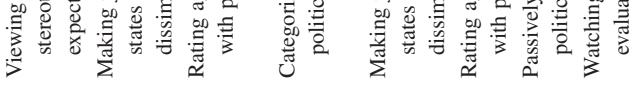
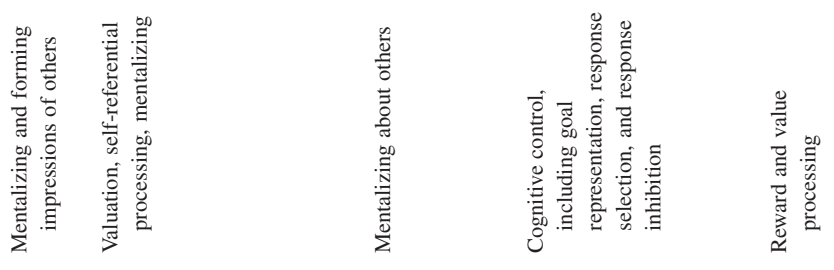

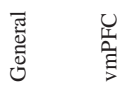

竞

尊

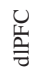

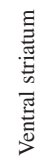


instance, Amodio and Devine (2006) observed that whereas the amygdala has a well-established role in basic affective and attentional processes, including responses to fear and threat (see LeDoux, 2000), it is not involved in the kind of high-level cognitive functions that support stereotyping (or other conceptual associations). Fear-conditioned responses can be learned very rapidly, often after a single exposure to the stimulus in a threatening context, and such associations may be difficult to extinguish (Bouton, 1994; but see Schiller et al., 2009). In addition, fear-conditioned responses are expressed primarily in autonomic responses (e.g., increased heart rate) and nonverbal behaviors (such as freezing and avoidance; see Dovidio, Kawakami, Johnson, Johnson, \& Howard, 1997; Fazio, Jackson, Dunton, \& Williams, 1995).

By contrast, conceptual associations, such as stereotypes, are known to form through a slower learning process that can be more easily extinguished and more directly expressed in trait impressions, deliberative decisions, and instrumental actions (see also Smith \& DeCoster, 2000). Based on neuroscientific investigations of conceptual knowledge and priming (Gabrieli, 1998; Martin, 2007), one would infer that stereotypic associations are likely to be stored in the temporal lobes and activated by regions of the dorsolateral PFC (Amodio, 2008). Consistent with the notion that prejudice (defined in terms of negative affect and evaluative bias) and stereotyping (defined in terms of beliefs and semantic associations) are distinct neurocognitive processes, Amodio and Devine (2006) demonstrated that implicit prejudice and stereotypic associations were in fact uncorrelated and that each was associated with a unique set of behavioral outcomes (see also Amodio \& Hamilton, 2012; Gilbert, Swencionis, \& Amodio, 2012). This line of research has been important because it integrated work from social psychology and cognitive neuroscience to illuminate basic mechanisms and suggest new hypotheses for the study of intergroup relations (see Amodio \& Ratner, 2011a).

\section{Using Neuroscience to Elucidate the Self-Regulation of Prejudice}

Despite pervasive evidence of implicit racial bias (e.g., see Jost et al., 2009, for a historical summary and review), some individuals - especially those who hold egalitarian worldviews - can become skilled at overriding their biases. Indeed, the human mind is fairly adept at self-regulation, and the brain is endowed with mechanisms for monitoring and correcting ongoing behavioral tendencies to keep them in check (Miller \& Cohen, 2001). Until recently, however, work on racial bias has lacked a process-oriented theory to explain how people detect the need for self-regulation in the first place and how different forms of control, such as the inhibition of a given response or the selection of an alternative response, are implemented (see Amodio \& Ratner, 2011b). The question of whether (and, if so, how) people are capable of controlling prejudicial impulses has fairly obvious implications for racial politics in general (e.g., see Sears et al., 2000).

Early models of the control of racial bias assumed that successful self-control depended upon situational and motivational affordances (i.e., whether one has the opportunity to correct an initial response; Devine, 1989; Fazio, 1990). However, researchers frequently observed that egalitarians (with similar racial attitudes and in identical situations) varied substantially in their abilities to respond without implicit bias (e.g., Devine, Plant, Amodio, \& Harmon-Jones, \& Vance, 2002), suggesting that the extant models of control were insufficient. Building on theories of cognitive control in the neuroscience literature, Amodio et al. (2004) proposed that the regulation of intergroup bias involves at least two mechanisms: (1) the detection of an undesirable response tendency (i.e., a "bias"), which should be associated with activity of the dorsal anterior cingulate cortex (ACC), and (2) the implementation of a more desirable, overriding (i.e., egalitarian) response, which should be associated with regions of the lateral prefrontal cortex (PFC; see Figure 1 and Table 1). Thus, despite harboring a strong personal commitment to responding without prejudice, some egalitarians might have difficulty detecting the need for control in the first place. This distinction between detection and implementation is critical when it comes to reducing prejudice. Whereas most interventions seek to 
foster a commitment to social justice, this work suggests that, for some people, what is needed is a personal strategy to help with detection and control.

Using event-related potential (ERP) measures, which track changes in brain activity on the order of milliseconds, Amodio and colleagues observed that the dACC was involved in the detection of unwanted stereotype activation and that this detection process operated independently of the implementation of control (see also Amodio, Kubota, Harmon-Jones, \& Devine, 2006; Bartholow, Dickter, \& Sestir, 2006). It was demonstrated subsequently that individual differences in conflict sensitivity — as indicated by ACC activity in response to implicit stereotype activation—could indeed help to explain why some egalitarians were more skilled at controlling their biases than others (Amodio, Devine, \& Harmon-Jones, 2008).

Amodio, Devine, and Harmon-Jones (2007) observed that the lateral PFC appears to play a useful role in the implementation of egalitarian responses. More specifically, participants who sought to regulate prejudice exhibited increased activity in the left lateral PFC, and this pattern of activity predicted behavioral intentions designed to reduce prejudice. Amodio (2010b) found that the relation between PFC activity and behavioral control of implicit bias was mediated by changes in rapid attention to racial cues. Several other studies using fMRI monitored activity in the ACC and PFC as participants viewed images of Black and White faces. Although the tasks used in these studies were not designed to explicitly assess the control of racial bias, the observed patterns of brain activity suggest that participants may have spontaneously engaged in processes of self-regulation (e.g., Cunningham et al., 2004; Lieberman et al., 2005; Richeson et al., 2003; Wheeler \& Fiske, 2005). Taken as a whole, this body of research has helped to unpack specific mechanisms of self-control in the context of intergroup relations, highlighting the various points at which control may fail in the sequence of mental operations. In doing so, this work provides a scientific basis for developing targeted interventions to reduce prejudice (Mendoza, Gollwitzer, \& Amodio, 2010; see also Beer et al., 2008; Gonsalkorale, Sherman, Allen, Klauer, \& Amodio, 2011; Monteith, Ashburn-Nardo, Voils, \& Czopp, 2002).

\section{Categorization and Perception of Race and Sex}

Although the social psychological literature on person perception suggests that attributes such as race and sex are categorized rapidly and automatically (Bodenhausen \& Macrae, 1998; Brewer, 1988; Fiske \& Neuberg, 1990), the specific timing and sequence of social categorization processes has been difficult to discern on the basis of behavioral measures alone. Several research teams have focused on ERPs to investigate the timing in which individuals are perceived, categorized, and stereotyped (Bartholow \& Amodio, 2009; Bartholow, Fabiani, Gratton, \& Bettencourt, 2001; Ito \& Cacioppo, 2000; Quadflieg \& Macrae, 2011). For instance, studies by Ito and Urland (2003) indicated that the categorization process involves multiple processing stages, and yet the brain registers a given target person's race in as little as 120 milliseconds and his or her sex within approximately 180 milliseconds. Other work revealed that stereotyping on the basis of race (Bartholow et al., 2003) and sex (Bartholow et al., 2001) occurs within 450 milliseconds—after the initial categorization, but before extensive conscious deliberation.

Recently, researchers have started to use neuroscientific methods to examine visual perceptions of race on the basis of physical markers of group membership (e.g., Amodio, 2010b; Brosch, Bar-David, \& Phelps, 2013; Caldara et al., 2003; Gilbert, Swencionis, \& Amodio, 2012; Kaul, Ratner, \& Van Bavel, 2013; Ofan, Rubin, \& Amodio, 2011; Ratner, Kaul, \& Van Bavel, 2012). Humans are expert face perceivers, and a large body of work has identified specific brain regions that appear to be dedicated to face processing, such as the fusiform gyrus (Kanwisher, McDermott, \& Chun, 1997; cf. Haxby, Hoffman, \& Gobbini, 2000). In an early fMRI study, Golby, Gabrieli, Chiao, and Eberhardt (2001) observed greater activity in the fusiform gyrus in response to own-race (vs. 
other-race) faces, and the magnitude of this difference predicted subsequent advantages in terms of recognition memory for own-race (vs. other-race) faces (see also Malpass \& Kravitz, 1969). Representations of race in the perceptual system are sensitive to visual information, such as skin tone and physiognomic features (Brosch et al., 2013; Gilbert et al., 2012; Ratner et al., 2013), as well as the goals and expectations of the perceiver (Amodio, 20110b; Gilbert et al., 2012; Kaul et al., 2013; Ofan et al., 2011, 2013; Ratner \& Amodio, 2013). In some ways, research on visual perception represents the newest frontier in the study of intergroup relations, and it provides yet another example of how neuroscience can offer unique insights when it comes to addressing long-standing questions in social and political psychology.

\section{The Existence of Partisan Bias and Motivated Political Cognition}

A significant challenge to rational choice models of political decision making, which assume that voters process politically relevant information more or less accurately, and, by extension, normative theories of democratic functioning is posed by strong behavioral evidence of motivated reasoning and partisan bias in the political domain (see Lavine, Jost, \& Lodge, in press). This evidence indicates that political information processing is prone to a host of self-serving, groupserving, and system-serving biases (Jost, Hennes, \& Lavine, 2013), such as tendencies to defend and bolster preexisting beliefs and opinions in the face of contradictory evidence (Taber \& Lodge, 2006). Motivational factors, including partisan and ideological goals, often guide and distort processes of reasoning and judgment (e.g., Kunda, 1990). The psychophysiological basis of motivated political reasoning was proposed a decade ago by Morris, Squires, Taber, and Lodge (2003), but only very recently have researchers begun to apply neuroscientific methods to probe the phenomenon in detail.

\section{Partisanship and Ingroup Favoritism}

Research suggests that attitudes toward social policies can be strongly influenced by partisan cues, independent of the policy's content and, in some cases at least, participants' ideological beliefs (e.g., Cohen, 2003). This finding is consistent with over 40 years of research on the phenomenon of ingroup favoritism, defined as the tendency to value members of one's own group more highly than members of other social groups (Tajfel, Billig, Bundy, \& Flament, 1971). More recently, studies in social neuroscience have found that merely assigning individuals to temporary, ad hoc (i.e., "minimal") social groups can influence basic cognitive and perceptual processes. Using ERP methods, Ratner and Amodio (2013) demonstrated that even arbitrary group distinctions led participants to process ingroup faces differently than out-group faces-and in just 170 milliseconds.

Van Bavel, Packer, and Cunningham $(2008,2011)$ randomly assigned participants to mixed-race experimental groups and found that seemingly automatic perceptual responses were sensitive to these assignments but not to racial distinctions. Specifically, participants exhibited heightened activity in the amygdala and the fusiform gyri in response to ingroup (vs. out-group) members, regardless of their race (see Van Bavel \& Cunningham, 2011 for a review). This pattern of ingroup bias emerged even in the absence of common visual cues distinguishing group membership (such as hair or shirt color), as well as the absence of preexisting stereotypes or a history of intergroup conflict. Other research suggests that assignment to a mixed-race experimental group can reduce subtle forms of racial bias (Van Bavel \& Cunningham, 2009, 2012). Taken in conjunction, this work indicates that even fairly minimal group-based affiliations can exert considerable influence over social cognition and behavior.

In political domains, ingroup favoritism may be intensified by a history of conflict and competition for limited resources (i.e., votes), differences in values and ideology, and the stereotypical exaggeration of actual differences. As a result, it is hardly surprising that partisan affiliations 
influence how individuals evaluate political candidates as well as policy proposals. In one of the first studies of neural correlates of political preferences, participants were instructed to classify faces of Democratic and Republican politicians that were paired with either positive or negative stimulus words (in the context of an Implicit Association Test; IAT) while their brains were scanned (Knutson et al., 2006). Results revealed that on attitude-congruent trials (when pleasant words were paired with political ingroup members or unpleasant words were paired with political out-group members), a network of frontal cortical structures including the ventromedial PFC - a region that is involved in the processing of subjective preferences-was activated. Furthermore, participants' implicit attitudes toward the parties (IAT scores) were correlated with amygdala activation during the presentation of attitude-congruent trials. Because the amygdala in involved in emotional reactivity and learning (e.g., Gallagher \& Chiba, 1996), Knutson and colleagues (2006) interpreted this pattern of activation as indicative of partisan bias at the neural level. However, it should be noted that these results are somewhat difficult to interpret, insofar as they could reflect neurocognitive processes associated with the basic categorization task rather than political attitudes per se. Nevertheless, this study was important because it took the first step in exploring the neural correlates of partisan political preferences.

\section{Differential Processing of Preferred and Nonpreferred Candidates}

The effects of partisanship have also been explored in the context of individuals' responses to overtly political content. In two parallel studies, Democrats and Republicans were asked to make judgments about Democratic (John Kerry) and Republican (George W. Bush) presidential candidates during the run-up to the 2004 U.S. election (Kaplan, Freedman, \& Iacoboni, 2007; Westen et al., 2006). In the first of these, participants were presented with a sequence of neutral and attitude-inconsistent information (i.e., evidence that their preferred candidates had made inconsistent statements) and, finally, exculpatory information (Westen et al., 2006). When partisans were confronted with attitude-incongruent information, they exhibited increased activity in the lateral and medial orbital PFC, ACC, insula, and posterior cingulate cortex (see Figure 1 and Table 1). Given that these regions are involved in the processing of pain, negative affect, error detection, and emotional appraisals (e.g., Baliki, Geha, Apkarian, 2009; Botvinick, Braver, Barch, Carter, \& Cohen, 2001; Vogt, 2005), the authors suggested that partisans experienced distress when they were faced with negative information about preferred candidates. However, when participants were invited to reflect on the incongruent information, they exhibited increased activation of the ventral striatum - a region frequently implicated in reward and value processing (Galvan et al., 2005). The study by Westen and colleagues is therefore intriguing because it suggests that exposure to attitude-incongruent information is distressing, but the opportunity to resolve inconsistencies through a process of explanation or justification may be physiologically as well as psychologically rewarding.

In a similar study, Kaplan and colleagues (2007) instructed Democrats and Republicans to view pictures of the major presidential candidates (Kerry, Bush, and Green Party candidate Ralph Nader) during a neuroimaging session. When viewing political out-group members, both Democrats and Republicans exhibited increased activity in several brain regions, including the insula, ACC, and multiple regions of the dorsolateral PFC. These patterns of activation were widely distributed, but the authors speculated — on the basis of prior research linking insula activity to the experience of disgust (Wicker et al., 2003) — that participants may have experienced (or even amplified) negative emotions when viewing candidates from opposing political parties. However, because participants were merely instructed to view pictures of candidates, it is unclear whether they experienced specific emotions or engaged in processes of emotional self-regulation. In the absence of a task that requires executive control, inferring the operation of controlled processes remains highly speculative (Aron 
et al., 2007; Poldrack, 2008). At the same time, these results are consistent with the broader notion that partisan affiliations reflexively bias neurocognitive responses to political candidates.

Some research suggests that partisan biases may operate even in the absence of explicit attention to political content (see Tusche, Kahnt, Wisniewski, \& Haynes, 2013). For instance, German participants who were flashed images of preferred (vs. nonpreferred) politicians exhibited greater activity in the insula, cingulate cortex, and ventral striatum (see Figure 1). These effects were observed despite the fact that their attention was drawn to an unrelated visual fixation task, suggesting that partisan biases may stimulate implicit evaluations of political candidates in the absence of a task requiring political judgment.

Of course, citizens who follow elections closely are subjected to a barrage of political messages and persuasive communications, so it is important to investigate attitude change processes, especially when it comes to partisans. During a scanning session, Kato and colleagues (2009) asked participants to evaluate the two major presidential candidates of 1992 (Democrat Bill Clinton and Republican George H.W. Bush) before and after watching campaign videos from that year. Participants who showed stronger dIPFC activity while watching negative videos about their preferred candidate became less positive toward him, whereas those who exhibited stronger mPFC activity while watching negative videos about their preferred candidate became more positive. Although prominent social psychological models of persuasion seek to explain attitude change in terms of a unitary process of "elaboration" (e.g., Petty \& Cacioppo, 1986), this pattern of activation suggests that slightly different neural systems may underlie positive and negative forms of attitude change towards political candidates. Research of this kind may ultimately help to shed light on the questions of when, why, and how people are likely to change their attitudes when they are confronted with political advertisements and other attempts at persuasion (e.g., see McGuire, 1985).

Other research suggests that exposure to attitude-congruent political information is inherently rewarding - at least for those who are interested in and engaged in politics. Gozzi, Zamboni, Krueger, and Grafman (2010) drew this conclusion after comparing the neural activity of participants who were high (vs. low) in terms of self-reported interest in politics, quantity of political media consumption, and frequency of political conversations while participants rendered judgments of agreement or disagreement with a series of political statements. Individuals who were more (vs. less) interested in politics exhibited stronger activation of the amygdala and ventral striatum when judging opinions with which they agreed. In light of behavioral evidence indicating that participants with greater political interest rate attitude-congruent statements as more positive and more emotionally intense - and the fact that the amygdala is linked to emotional salience (Anderson \& Phelps, 2001; Cunningham et al., 2008; Whalen, 1998) and the ventral striatum is linked to reward processing (Galvan et al., 2005; O'Doherty, 2004) - there is reason to assume that political junkies find exposure to ideas with which they agree to be arousing and intrinsically satisfying. If so, there could be a powerful physiological feedback loop that contributes to political polarization by incentivizing selective exposure to information that validates preexisting opinions (e.g., Sears \& Freedman, 1967). Our own work — and that of others — suggests that there may be left-right ideological differences in the extent to which individuals are willing to expose themselves to politically incongruent information (Garrett, 2009; Iyengar, Hahn, Krosnick, \& Walker, 2008; Nam, Jost, \& Van Bavel, 2013). Future research in political neuroscience would do well to follow up on this possibility, especially given the litany of psychological and neural correlates of political orientation that we review later in the chapter (see also Hibbing et al., in press; Jost \& Amodio, 2012).

At the same time, partisans from quite different cultures may have more in common than one might assume when it comes to evaluating political candidates. Although some work suggests that Americans tend to prioritize power (or dominance) whereas Japanese tend to prioritize warmth when evaluating and selecting political candidates, both American and Japanese participants were found to exhibit stronger bilateral amygdala activation when they viewed faces of political candidates for 
whom they would (vs. would not) vote (Rule et al., 2010). Because the amygdala plays a prominent role in responding to rewards, threats, and other emotionally salient events (e.g., Cunningham, Van Bavel, \& Johnsen, 2008; Holland \& Gallagher, 1999; Whalen, 1998), the authors concluded that there may be a universal association between emotional arousal and voting intentions. This work highlights one potential advantage of neuroimaging research: that it can help to illuminate ways in which seemingly disparate behavioral outcomes can mask deeper, underlying similarities in the processing of information and opinion.

\section{Simulating the Mental States of Ingroup Versus Out-Group Members}

Another advantage of neuroimaging techniques is that they can help to disentangle the multiplicity of neural systems involved in complex cognitive operations. For instance, work by Mitchell, Macrae, and Banaji (2006) suggests that political partisans process the mental states of fellow ideologues differently than those who hold divergent opinions. During neuroimaging, Harvard undergraduates were asked to make sequential judgments about the mental states of a liberal target, a conservative target, and themselves. When students were instructed to think about those who were ideologically similar to themselves, they exhibited increased activation of the vmPFC, a region that is sometimes associated with self-referential processing (e.g., Macrae, Moran, Heatherton, Banfield, $\&$ Kelley, 2004). By contrast, when these students were asked to make judgments about those who were ideologically dissimilar, they exhibited increased activation of the dmPFC, a region that is associated with thinking about the mental states of others but seems to be unrelated to self-referential processing (Mitchell, Heatherton, \& Macrae, 2002). ${ }^{1}$ Mitchell and colleagues proposed that the "simulation" of mental states is facilitated for fellow ideologues (and inhibited for ideological out-group members) - a notion that has fairly obvious but nonetheless profound implications for perspective taking, negotiation, and the resolution of political conflicts (see Krochik \& Jost, 2011). Other work suggests not only that individuals show more (verbal and nonverbal) signs of empathy when it comes to ingroup (vs. out-group) members (Cikara, Bruneau, \& Saxe, 2011), but that the magnitude of the "empathy gap" (measured in terms of neurological responses) predicts willingness to mistreat out-group members (Hein, Silani, Preuschoff, Batson, \& Singer, 2010). It is hardly a stretch to suggest that partisan gridlock may stem, at least in part, from a lack of perspective taking and empathy for members of a competing political party.

Social psychologists have long assumed that impressions of other people may be more influenced by stereotypes and social categories than by personalized, individuating information (e.g., Macrae \& Bodenhausen, 2000). However, stereotypic expectations are often violated during the period of impression formation (Hamilton, Driscoll, \& Worth, 1989; Hastie \& Kumar, 1979; Macrae, Bodenhausen, Schloerscheidt, \& Milne, 1999; Sherman, Lee, Bessenoff, \& Frost, 1998)—such as when a politician endorses policy positions that deviate from that of his or her party. Although neuroimaging studies have largely focused on the neural substrates associated with categorical, stereotype-based responses (Gilbert et al., 2012; Mitchell, Ames, Jenkins, \& Banaji, 2009; Quadflieg et al., 2009; Wheeler \& Fiske, 2005), one study has examined neural responses to expectancy violations in a political context (Cloutier, Gabrieli, O'Young, \& Ambady, 2011). Students at MIT were presented with photographs of 80 unfamiliar Democratic and Republican politicians who were paired

\footnotetext{
${ }^{1}$ Mitchell et al. (2006) did not statistically compare liberals and conservatives, but close inspection of their figures (p. 657) suggests that the decrease in ventral mPFC activation in response to out-group (i.e., "liberal other") targets for participants who were "dissimilar from liberal" (i.e., more conservative) might have been larger than the corresponding decrease for liberal participants who responded to conservative targets (Figure 2A). Similarly, conservatives seemed to show greater activation of dorsal mPFC in response to liberals than liberals showed in response to conservatives (Figure 2B). Future research would do well to investigate potential ideological asymmetries with respect to neural markers of empathy and perspective taking, in light of other evidence reviewed in this chapter.
} 
with views that were either typical or atypical of their party (e.g., "wants a smaller government" or "wants liberal supreme court judges") and asked to form impressions of the targets. As hypothesized, brain regions associated with mentalizing - including the medial prefrontal cortex and temporoparietal junction (Adolphs, 2009; Amodio \& Frith, 2006; Mitchell et al., 2006; Saxe \& Wexler, 2005; Spreng, Mar, \& Kim, 2009)—were more active when participants viewed nonstereotypical targets, such as a Democrat who preferred smaller government or a Republican who supported liberal supreme court judges. The authors speculated that exposure to expectancy-violating politicians caused participants to individuate them and, in so doing, to recruit brain regions that are required for mentalizing (cf. Brewer, 1988; Fiske \& Neuberg, 1990; Macrae et al., 1999). The implication is that people may think more deeply about the mental states of politicians who deviate from their parties' official platforms. More speculatively, the enforcement of "party loyalty" and ingroup consensus could serve to reduce empathy and contribute to a lack of respect for individual politicians.

\section{The Nature of Left-Right Differences in Political Orientation}

Although the political meanings of the terms "left" and "right" are most clearly vestiges of the French Revolution, several authors have suggested that the substantive distinction is in fact much older than 1789 (e.g., see Noël \& Thérien, 2008). Indeed, their ideological connotations seem to be linked to pervasive cultural assumptions in Indo-European societies concerning handedness and dominance (McManus, 2002). More than a century ago, for instance, Hertz (1909) wrote that "the right hand is the symbol and model of all aristocracy, the left hand of all common people" (p. 89). LaPonce (1981) similarly observed that throughout Medieval Europe the right was the "side of God" and was "universally associated with the notion of privilege, dominance, and sacredness" (p. 10). Philosophical differences between the left and right concerning views of human nature, power, majority-minority relations, and systems of distributive justice are frequently traced to debates originating in ancient Greece (e.g., see Noël \& Thérien, 2008; Raphael, 2001; Tarnopolsky, 2010). In this section of the chapter, we suggest that philosophical differences such as these may be linked to underlying variability in brain structure and function. Or, as Taber and Young (2013, p. 549) put it, "what we believe" is related to "how we think."

\section{Resistance to Change, Acceptance of Inequality, and System Justification}

There are many different but related ways of thinking about the core values that divide the political right from the left (or, in the United States and elsewhere, conservatism from liberalism), but Jost and his colleagues (Glaser, Kruglanski, \& Sulloway, 2003; Jost, Nosek, \& Gosling, 2008; Jost et al., 2009) have noted that two major dimensions are most commonly emphasized: (1) resisting versus advocating social change (that is, maintaining vs. challenging tradition) and (2) accepting versus rejecting inequality (that is, challenging vs. maintaining hierarchy). Thus, Inglehart (1989) — like many others (e.g., Erikson, Luttbeg, \& Tedin, 1988; Fuchs \& Klingemann, 1990; Lipset, Lazarsfeld, Barton, \& Linz, 1954/1962; McClosky \& Zaller, 1984)-boils it down to "whether one supports or opposes social change in an egalitarian direction" (p. 293). Jost, Federico, and Napier (2013) have proposed that system justification, defined as the psychological tendency to defend, bolster, and justify aspects of the status quo, is:

the motivational "glue" that holds the two dimensions of left-right ideology together. To vindicate and uphold traditional institutions and arrangements, conservatives are bound to defend extant inequalities as just and necessary. Conversely, to bring about a more equal state of affairs, progressives are obliged to criticize existing institutions and practices. (p. 236) 


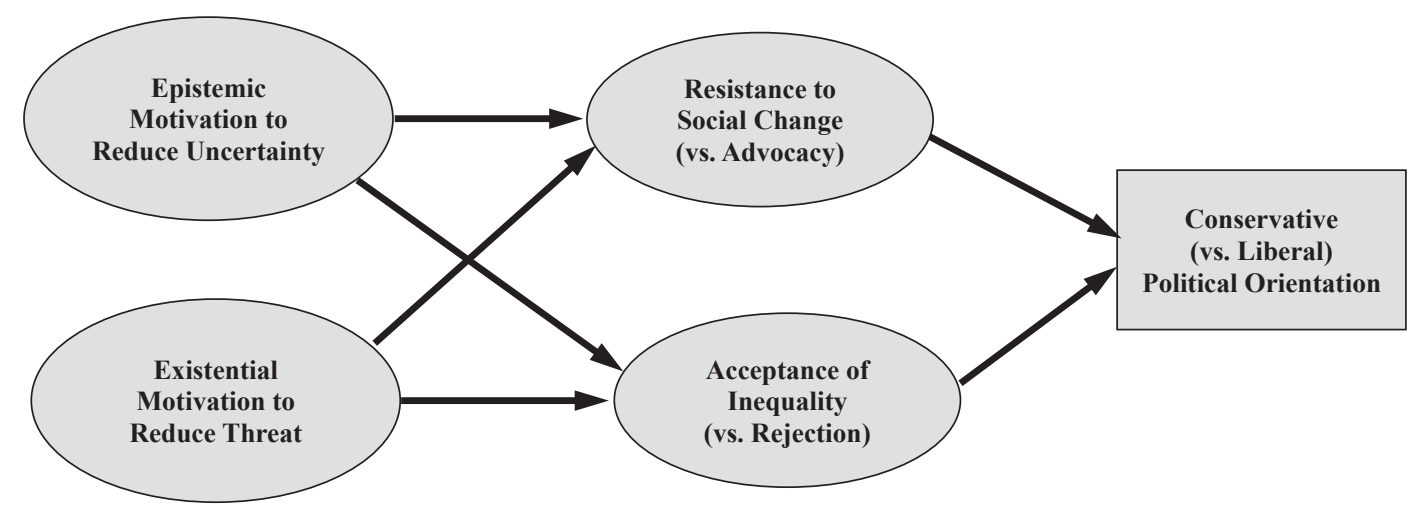

Figure 2. Schematic illustration of the theory of political ideology as motivated social cognition (Adapted from Jost, 2009).

Ideological differences with respect to the two core values are manifested even at an implicit level of awareness. Studies employing the IAT - a measure of implicit evaluative associations-reveals that conservatives exhibit preferences for stability, tradition, duty, and command, whereas liberals exhibit preferences for opposite values, such as flexibility, progress, compromise, diversity, and feminism (Jost, Nosek, \& Gosling, 2008; Smith et al., 2011b).

Research on the underlying personality characteristics of liberals (or leftists) and conservatives (or rightists) began in the aftermath of the Second World War (e.g., Adorno, Frenkel-Brunswik, Levinson, \& Sanford, 1950; Allport, 1954; McClosky 1958). Drawing on these early contributions_-as well as subsequent work by Rokeach (1960), Tomkins (1963), Wilson (1973), Tetlock (1983), and Sidanius (1985) — Jost et al. (2003) theorized that social and political attitudes concerning tradition (vs. social change) and inequality are linked to underlying epistemic and existential motives having to do with the management of uncertainty and threat (see Figure 2). They also reported the results of a meta-analytic review of 88 studies conducted in 12 countries between 1958 and 2002, which established that situational and dispositional variability in psychological orientations toward uncertainty and threatening stimuli were related to left-right political orientation. Specifically, death anxiety, fear of threat and loss, system threat, mental rigidity, intolerance of ambiguity, and personal needs for order, structure, and closure were all positively associated with conservatism (or negatively associated with liberalism). By contrast, openness to new experiences, cognitive complexity, tolerance of uncertainty, and self-esteem were all positively associated with liberalism (or negatively associated with conservatism).

There is now abundant evidence from research sites around the world using a wide range of methodological techniques leading to the conclusion that there are indeed ideological asymmetries in cognitive and motivational functioning. Specifically, a decade of research has replicated and extended the results of Jost et al.'s (2003) analysis by demonstrating each of the following:

1) Political conservatism and right-wing orientation are associated with higher scores on measures of general, economic, and political system justification (Jost et al., 2008; see also Chambers, Schlenker, \& Collisson, 2013; Cichocka \& Jost, 2013; Hennes, Nam, Stern, \& Jost, 2012; Jost, West, \& Gosling, 2009; Lammers \& Proulx, 2013; Pacilli, Taurino, Jost, \& Van der Toorn, 2011);

2) Resistance to change and acceptance of inequality are correlated with one another, and they are generally (but not always) associated with system justification, political conservatism, and right-wing orientation (Aspelund, Lindeman, \& Verkasalo, 2013; Jost et al., 2007; Kandler, Bleidorn, \& Riemann, 2012; Lammers \& Proulx, 2013; Piurko, Schwartz, \& Davidov, 2011; Vecchione, Caprara, Dentale, \& Schwartz, 2013); 
3) Personal needs for order, structure, and cognitive closure are positively associated with resistance to change, acceptance of inequality, system justification, political conservatism, and right-wing orientation (Chirumbolo, Areni, \& Sensales, 2004; Critcher, Huber, Ho, \& Koleva, 2009; Dollinger, 2007; Federico, Ergun, \& Hunt, 2013; Federico \& Goren, 2009; Golec de Zavala \& Van Bergh, 2007; Hennes et al., 2012; Jost et al., 2007; Keller, 2005; Kemmelmeier, 2007; Nam et al., 2013; Sargent, 2004; Shook \& Fazio, 2009; van Hiel, Pandelaere, \& Duriez, 2004);

4) Situational activation of epistemic needs to reduce uncertainty or to attain a sense of control or closure tends to increase the appeal of system justification, political conservatism, and right-wing orientation (Eidelman, Crandall, Goodman, \& Blanchar, 2012; Kay, Gaucher, Napier, Callan, \& Laurin, 2008; Kay et al., 2009; Lammers \& Proulx, 2013; Rock \& Janoff-Bulman, 2010; Rutjens \& Loseman, 2010; Thorisdottir \& Jost, 2011);

5) Personal concern for and sensitivity to dangerous and threatening stimuli are positively associated with resistance to change, acceptance of inequality, and political conservatism (Carraro, Castelli, \& Macchiella, 2011; Jost et al., 2007; Matthews, Levin, \& Sidanius, 2009; Onraet, Van Hiel, Dhont, \& Pattyn, 2013; Oxley et al., 2008; van Leeuwen \& Park, 2009; Vigil, 2010; Weber \& Federico, 2007);

6) Situational activation of existential needs to manage fear and anxiety often increases the appeal of system justification, political conservatism, and right-wing orientation (Bonanno \& Jost, 2006; Burke, Kosloff, \& Landau, 2013; Nail \& McGregor, 2009; Nail, McGregor, Drinkwater, Steele, \& Thompson, 2009; Thorisdottir \& Jost, 2011; Ullrich \& Cohrs, 2007);

7) In terms of "Big Five" personality characteristics, openness to new experiences is positively associated with liberal, left-wing orientation, whereas conscientiousness (especially the need for order facet) is positively associated with conservative, right-wing orientation (Carney, Jost, Gosling, \& Potter, 2008; Gerber, Huber, Doherty, \& Dowling, 2010; Hirsh, DeYoung, Xu, \& Peterson, 2010; Jost et al., 2009; Mondak, 2010; Rentfrow, Jost, Gosling, \& Potter, 2009);

8) Childhood measures of intolerance of ambiguity, uncertainty, and complexity as well as sensitivity to fear, threat, and danger predict conservative orientation later in life (Block \& Block, 2006; Fraley, Griffin, Belsky, \& Roisman, 2012); and

9) Political conservatives report being happier and more satisfied than liberals, and this effect is partially mediated by system justification and acceptance of inequality (Choma, Busseri, \& Sadava, 2009; Cichocka \& Jost, 2013; Napier \& Jost, 2008; Schlenker, Chambers, \& Le, 2012).

Increasingly, researchers are turning to physiological methods, especially neuroscientific methods, to examine the cognitive and motivational bases of ideology. Such work is especially valuable because it helps to illuminate the origins, manifestations, and consequences of ideological preferences as well as the specific processes by which ideology affects judgment and behavior (for reviews, see Hibbing et al., in press; Jost \& Amodio, 2012).

To the extent that some neurocognitive mechanisms are automatic and therefore relatively impervious to conscious monitoring and control, research in political neuroscience has the advantage of circumventing limitations associated with traditional methods of self-report, including response biases associated with self-presentational and social desirability concerns (cf. van Hiel, Onraet \& De Pauw, 2010). In some cases, there may be ideological differences at the level of cognitive or affective processing even in the absence of differences in behavioral outcomes (e.g., Schreiber et al., 2013). Our review of the literature is highly consistent with that of Taber and Young (2013), who concluded that: "It is now clear that liberals and conservatives differ in terms of uncontrolled physiological responses to stimuli, brain function, and even static brain anatomy" (p. 541). Political neuroscience, in other words, has given researchers a new and unprecedented ability to observe underlying processes that are associated with ideological outcomes. 


\section{Differences in Brain Activity as a Function of Political Orientation}

Drawing on Jost et al.'s (2003) model of political ideology as motivated social cognition, Amodio and colleagues (2007) reasoned that liberals and conservatives might differ in conflict monitoring, a neurocognitive process that functions to detect discrepancies between inconsistent response tendencies (Botvinick et al., 2001). The study was somewhat unique in that the primary research goal was not to identify neural substrates per se, but to leverage scientific understanding about known patterns of neural activity to inform and test a novel hypothesis about differences in conflict monitoring as a function of political orientation. In the context of a "Go/No-Go task," participants were instructed to respond as quickly as possible to a frequently presented ("Go") stimulus, so that these responses became habitual. On a small proportion of trials, however, a "No-Go" stimulus appeared; for these trials, participants were instructed to withhold their habitual responses. Conflict detection-the process of detecting a conflict between one's intention and a prepotent response tendency, which is evoked by laboratory tasks such as the Go/No-Go, Stroop, and Eriksen flankers tasks-is associated with brain activity in the ACC (e.g., Carter et al., 1998; Gehring, Goss, Coles, Meyer, \& Donchin, 1993). Research has also linked ACC activity to the detection of automatic racial biases (Amodio et al., 2004) and individual differences in the motivation to respond without prejudice (Amodio \& Devine, 2006; Amodio et al., 2008).

Political orientation was indeed correlated with performance on the Go/No-Go task as well as concurrent patterns of brain activity (measured in terms of $\mathrm{N} 2$ and error-related negativity [ERN] amplitudes) in samples of NYU and UCLA undergraduates (see Table 2). More specifically, selfreported liberalism, which was strongly correlated with voting for John Kerry over George W. Bush in the 2004 election, was associated with behavioral accuracy on No-Go trials (i.e., successful attempts to withhold prepotent responses). In addition, liberals exhibited larger ERN amplitudes, indicating greater brain activity in the ACC on No-Go trials, even after adjusting for behavioral accuracy. These results support the hypothesis that political orientation is partially rooted in basic neurocognitive mechanisms - such as those involved in conflict monitoring - that are implicated in the processing of new, unexpected, and potentially contradictory pieces of information (see also Shook \& Fazio, 2009). Studies such as this may help to explain how and why liberals and conservatives differ when it comes to psychological needs for order, structure, and closure as well as epistemic orientations concerning ambiguity, uncertainty, and complexity (Jost et al., 2003; Jost et al., 2007; Jost et al., 2009).

Table 2. Correlations Between Political Orientation and Measures of Voting Behavior, Task Performance, and ACC Activation in the Context of a Go/No-Go Experiment

Correlation with Political Orientation (Liberalism-Conservatism)

Self-reported voting behavior in 2004 (Bush vs. Kerry)

Accuracy on No-Go trials $.79 * * *$

$-.30 *$

No-Go N2 amplitudes

$-.41 * *$

ERN amplitudes

$-.59 * * *$

ERN amplitudes adjusting for accuracy

$-.53 * * *$

\footnotetext{
Note. This table summarizes the results of an experiment reported by Amodio et al. (2007). Political orientation was measured in terms of ideological self-placement on a scale ranging from -5 ("extremely liberal") to 5 ("extremely conservative"), so higher scores indicate greater conservatism. For this table, the ERN and N2 amplitudes, both of which are negative-going waveforms, were reverse-scored, so that more positive values indicate greater ACC activity. All correlations are based on a sample size of 41 college students from University of California, Los Angeles and New York University, except for the correlation with voting behavior, which is based only on those 21 participants who reported voting in the 2004 presidential election.

$* p<.05, * * p<.01, * * * p<.001$
} 
Weissflog, Choma, Dywan, van Noordt, and Segalowitz (2013) replicated the results of the Amodio et al. (2007) study in a sample of undergraduates in Canada. They observed that selfreported liberalism, attitudinal rejection of inequality, and low scores on right-wing authoritarianism were all associated with greater ACC activity on No-Go trials, as measured in terms of N2 (and, less consistently, ERN) amplitudes. ${ }^{2}$ This general line of work demonstrates that the application of theory and methods from neuroscience can inspire political psychologists to make discoveries that spawn new and additional hypotheses - in this case, hypotheses concerning the relationship between political ideology and self-regulation-that were neither planned nor envisioned on the basis of behavioral research alone.

To further probe liberal-conservative differences in attention and conflict monitoring, McLean et al. (2013) administered the "flanker task," which requires participants to attend to a series of target stimuli (in this case, faces) in the center of a display and to ignore potentially distracting stimuli (other faces, which may be either congruent or incongruent with the target in terms of emotional expression). Consistent with the notion that conservatives are more vigilant than liberals when it comes to potential threats in the environment (e.g., Hibbing et al., in press; Jost et al., 2003; Oxley et al., 2008; Vigil, 2010), this study revealed that conservatives displayed enhanced sensitivity to angry (but not happy) target faces, as revealed by reaction time indicators of attentional narrowing.

To better understand the genetic and social transmission of political attitudes, Dennis, Jost, Amodio, O'Toole, and Medina (2013) investigated the relationship between parental political orientation and young children's neural sensitivity to cognitive conflict (measured in terms of the N2 component). The EEG activity of children between the ages of five and seven was recorded while they completed an age-appropriate flanker task. Consistent with the results of McLean et al. (2013), effects of political orientation were observed only in the context of being presented with angry (i.e., threatening) faces, so that conflict-related N2 amplitudes on these trials were larger among children of liberals (and moderates) than conservatives. This pattern of results conceptually replicates, in children, an effect of political orientation on neurocognitive functioning that was documented in a study of adults by Amodio et al. (2007) and provides evidence concerning the cross-generational transmission of political orientation in a manner that is consistent with Jost et al.'s (2003) theoretical model of ideology as motivated social cognition.

\section{Political Orientation and Hypodescent in Racial Classification}

Following the repeal of antimiscegenation laws and the gradual normalizing of Black-White relationships in the long and painful wake of slavery, the United States has become a truly multiracial society. At the same time, mixed-race individuals are commonly described in monoracial terms, with Black/White biracial targets often classified as "Black" rather than "White." The tendency to categorize multiracial individuals according to their most socially subordinate group membership reflects the principle of hypodescent, which is associated with the notorious "one drop rule" in U.S. history. Social psychological research reveals that the principle of hypodescent characterizes racial categorization even today (Halberstadt, Sherman, \& Sherman, 2011; Ho, Sidanius, Levin, \& Banaji, 2011; Peery \& Bodenhausen, 2008).

To the extent that political conservatives are more supportive of the traditional social order and more accepting of inequality than are liberals, Krosch, Berntsen, Amodio, Jost, and Van Bavel (2013a) hypothesized that political orientation would moderate racial categorization under circumstances of ambiguity. In three studies, it was observed that conservatives exhibited stronger reliance

\footnotetext{
${ }^{2}$ Inzlicht, McGregor, Hirsh, and Nash (2009) observed that religiosity was negatively associated with ERN amplitudes in response to errors made during a Stroop (color naming) task. Given the relatively strong correlation between religiosity and conservatism (e.g., Olson \& Green, 2006), this result is also consistent with the notion that ideological differences in epistemic motivation may be linked to neurocognitive responses to conflict.
} 
on the principle of hypodescent, using a more lenient threshold than liberals in categorizing mixed race faces as Black. Consistent with the notion that system justification motivation helps to explain this phenomenon, the relationship between political orientation and racial categorization was: (1) statistically mediated by individual differences in opposition to equality and (2) stronger when U.S. participants believed that they were classifying "American" rather than "Canadian" faces.

A follow-up study was conducted to assess whether ideological differences in racial categorization are driven by differences in the subjective categorization of mixed-race faces or more basic differences in the representation of objective visual features (i.e., "Blackness"; Krosch, Jost, \& Van Bavel, 2013b). Forty-five White participants completed a self-report questionnaire assessing political orientation (i.e., liberalism-conservatism). At a later date, they were invited to complete a racecategorization task during neuroimaging. Consistent with previous research (Ronquillo et al., 2007), brain activity in the amygdala and anterior insula was positively correlated with the objective Blackness of the faces. Importantly, individual differences in political orientation moderated the relationships between objective face "Blackness" and insula activity, so that conservatism was associated with stronger insula activity in response to morphed faces reflecting a higher proportion of Black (vs. White) ancestry. This research illustrates one way in which neuroimaging techniques can be used to tease apart separate psychological mechanisms that may be difficult to disentangle at the level of judgment or behavior. In this case, it may also help to explain how, why, and when multiracial individuals are likely to be categorized as members of their most subordinate racial group - a phenomenon that may enhance their vulnerability to discrimination and exacerbate existing inequalities.

\section{Differences in Physiological Reactivity as a Function of Political Orientation}

To investigate the hypothesis that responses to threat are linked to political orientation, Oxley et al. (2008) conducted a physiological study involving adult residents of Lincoln, Nebraska. In a prescreening session, participants were asked about their preferences with respect to a range of policy issues, including military spending, the death penalty, the Patriot Act, school prayer, immigration, gun control, foreign aid, pacifism, gay marriage, and abortion. In a separate session, Oxley et al. measured the physiological responses of strong liberals and strong conservatives (inferred on the basis of their policy preferences) to two different types of threatening stimuli. In one task, participants viewed a series of images that included some especially threatening images (i.e., a bloodied face, a large spider on a person's face, and a maggot-infested open wound) as well as neutral and positive images (e.g., a bowl of fruit, a cute rabbit, and a happy child). Oxley and colleagues observed that individuals who expressed more conservative policy preferences exhibited heightened skin conductance responses (SCRs) — an index of autonomic arousal—in response to negative (i.e., threatening and disgusting) images, in comparison with those who held more liberal positions. There were no ideological differences with respect to SCRs following exposure to neutral and positive images.

In a second task, Oxley et al. (2008) administered sudden, unexpected blasts of white noise and measured startle blink responses while participants regarded a fixation point on a computer monitor. More forceful contraction of the muscles surrounding the eyes typically reflects a more defensive or fearful reaction to the startling stimulus (Hess, 2009). Although participants in general exhibited reflexive eye blinks in response to noise blasts, conservatives exhibited stronger blink amplitudes than did liberals (after adjusting for demographic factors). Given that amygdala activation tends to accompany the startle reflex in response to aversive stimuli (Anders, Lotze, Erb, Grodd, \& Birbaumer, 2004), it is quite conceivable that liberal-conservative differences in blinking responses reflect differences in amygdala function. However, it should be noted that a clear inference about the relationship between the amygdala and political orientation cannot be drawn on the basis of this 
study, insofar as the startle response was assessed during unconstrained resting periods between trials - which is typically treated as a "baseline" measure-rather than in the context of processing emotionally relevant stimuli (see Lang et al., 1990). It is also unclear whether these responses were caused by the presentation of threatening or disgusting stimuli in particular or to negativity in general.

Indeed, left-right differences in brain and behavior have been observed with respect to disgust sensitivity. Self-reported sensitivity to disgust (especially when it comes to cleanliness and purityrelated issues) is associated with the endorsement of more socially and politically conservative attitudes (e.g., Inbar, Pizarro, \& Bloom, 2009; Inbar, Pizarro, Knobe, \& Bloom, 2009; but see Tybur, Merriman, Hooper, McDonald, \& Navarrete, 2010). Even a simple reminder of hand sanitization leads people to express more conservative (and less liberal) attitudes and judgments (Helzer \& Pizarro, 2011). It appears that there are also physiological differences in sensitivity to disgust as a function of political orientation. Smith, Oxley, Hibbing, Alford, and Hibbing (2011a) measured the skin conductance of participants as they viewed disgusting images (i.e., a man with a mouthful of worms, an emaciated body, feces in a toilet, a bloody wound, and an open sore filled with maggots). They found that - after adjusting for age, sex, education, and even self-reported disgust sensitivityparticipants who exhibited stronger GSR following exposure to disgusting images were more likely to oppose gay marriage and premarital sex. However, attitudes concerning other societal issues, such as free trade, foreign aid, immigration, and tax cuts, were unrelated to GSR. In summary, then, this study provided some, albeit mixed, evidence that heightened physiological sensitivity to disgusting (as well as threatening) stimuli is associated with more conservative political orientation.

Feldman (2013) has asked: "Are the effects of conflict monitoring (Amodio et al., 2007) and physiological reactions to threatening stimuli (Oxley et al., 2008) on ideology understandable from a single theoretical perspective?" (p. 618). We would answer in the affirmative. If it is true that conservative ideology, with its emphasis on tradition, hierarchy, and maintenance of the status quo, provides a better match than liberal or progressive ideology to epistemic and existential motives to reduce uncertainty and threat (Jost et al., 2003), then we would indeed expect to see neurocognitive differences involving the ACC, amygdala, and insula as a function of political orientation (see also Jost \& Amodio, 2012). Indeed, we find, with Taber and Young (2013), that "the neuroimaging literature seems largely to parallel, if not outright confirm, other, typically trait- and survey-based research suggesting liberal thinking, relative to conservative, is related to greater cognitive flexibility, more empathy, and less concern with fear" (p. 541).

\section{Differences in Brain Structure as a Function of Political Orientation}

In light of robust evidence of cognitive-motivational differences between liberals and conservatives in terms of uncertainty and threat management, recent work has begun to investigate the possibility that ideological differences are manifested in neuroanatomical structures. Kanai, Feilden, Firth, and Rees (2011) hypothesized that liberals and conservatives would exhibit differences in grey-matter volume with respect to the ACC and amygdala, especially in light of evidence that amygdala volume is positively correlated with dispositional fearfulness (van der Plas, Boes, Wemmie, Tranel, \& Nopoulos, 2010). In two samples of British university students, Kanai and colleagues observed that conservatism (measured in terms of ideological self-placement) was positively associated with larger right-amygdala volume (see Table 3), which is conceptually consistent with the earlier finding that conservatism is associated with greater physiological startle response to threatening stimuli (Oxley et al., 2008).

The researchers also discovered that greater liberalism (or lesser conservatism) was associated with larger ACC volume, which is conceptually consistent with the finding that liberalism is associated with greater conflict-related activity in the ACC (Amodio et al., 2007; see also Dennis 
Table 3. Correlations Between Political Orientation and Regional Brain (Grey Matter) Volume (Kanai et al., 2011)

\begin{tabular}{|c|c|c|}
\hline \multirow[b]{2}{*}{ Brain region } & \multicolumn{2}{|c|}{$\begin{array}{c}\text { Correlation with } \\
\text { Political Orientation } \\
\text { (Liberalism-Conservatism) }\end{array}$} \\
\hline & $\begin{array}{l}\text { Study } 1 \\
(N=90)\end{array}$ & $\begin{array}{c}\text { Study } 2 \\
(N=\mathbf{2 8})\end{array}$ \\
\hline $\mathrm{ACC}$ & $-.27 * *$ & $-.49 * *$ \\
\hline Right amygdala & $.23^{*}$ & $.38 *$ \\
\hline Left insula & $.42 \dagger$ & $.55^{* *}$ \\
\hline \multicolumn{3}{|c|}{$\begin{array}{l}\text { Note. This table summarizes the results of a study reported by } \\
\text { Kanai et al. (2011). Political orientation was measured in terms of } \\
\text { ideological self-placement on a scale ranging from } 1 \text { ("very } \\
\text { liberal") to } 5 \text { ("very conservative"), so that higher scores indicate } \\
\text { greater conservatism. Correlations for both studies are based on } \\
\text { samples of college students from University College London. } \\
{ }^{*} p<.05 \text {, corrected for family-wise error (FWE) } \\
* * p<.01 \text {, corrected for family-wise error (FWE) } \\
\dagger p<.001 \text {, uncorrected and cluster size larger than } 50 \mathrm{~mm}^{3}\end{array}$} \\
\hline
\end{tabular}

et al., 2013; Weissflog et al., 2013). In a more exploratory analysis of the whole brain, Kanai et al. (2011) observed that conservatism was associated with larger grey matter volume in the left insula. This, too, is consistent with previous work, most notably demonstrations that conservatives are more sensitive to disgust (Inbar et al., 2009) and that the insula plays a pivotal role in the experience of disgust (Wicker et al., 2003).

To understand why there are ideological differences in regional brain volume, Nam, Jost, Campbell-Meiklejohn, and Van Bavel (2013) focused on the relationship between system justification tendencies and neuroanatomical structure in an American sample. As we noted earlier, system justification theory holds that people are motivated to defend and bolster existing social, economic, and political arrangements because doing so addresses basic psychological needs, including epistemic needs to attain certainty and order. System justification is a key aspect of political conservatism, insofar as both are concerned with resistance to change, maintenance of the status quo, and justification of inequality (Jost, Nosek, \& Gosling, 2008). Given that the amygdala is associated with responses to uncertainty, threat, and other motivationally salient stimuli (e.g., Cunningham et al., 2008; Phelps et al., 2001; Whalen, 2007), Nam, Jost, Campbell-Meiklejohn, et al. (2013) hypothesized that system-justifying tendencies would be associated with greater amygdala volume. They observed that system-justification scores were indeed associated with greater bilateral amygdala volume in a sample of 48 U.S. college students (adjusting for the effects of age, sex, and overall brain volume, as well as political orientation). A path model suggested that discomfort with uncertainty mediated the relationship between system justification and amygdala volume to a marginal degree. These results suggest that system justification, like political conservatism, may be reflected in specific neuroanatomical structures.

\section{Differences in Resting-State Connectivity as a Function of Political Orientation}

Given that individual differences in political orientation seem to be associated with fundamental cognitive and motivational orientations (Jost et al., 2003; Oxley et al., 2008), there is reason to suppose that political orientation is also associated with the intrinsic functional architecture of the brain. Building on work showing that liberalism is associated with increased conflict-related processing in the dorsal ACC (Amodio et al., 2007) as well as increased grey-matter volume in this 
region (Kanai et al., 2011), Cox et al. (2012) examined the relationship between political orientation and intrinsic functional connectivity - the interrelationship between different brain regions when people are at rest-using the dorsal ACC as a seed region. Results revealed that liberalism was indeed positively associated with intrinsic functional connectivity between the dACC and the right insula and putamen-part of a network of regions that process emotionally significant stimuli (Seeley et al., 2007). Although these results are preliminary, they are consistent with the notion that liberals may possess tighter integration of neurocognitive systems that are involved in cognitive control (especially conflict monitoring) and affective representation. Another study by Newman-Norlund, Burch, and Becofsky (2013) indicated that Democrats exhibited stronger restingstate connectivity than Republicans with respect to the so-called human mirror-neuron system, which is a network linked to a host of social and emotional abilities, including empathy. Taken together, these findings suggest that political orientation may be related, not only to specific situational responses to stimuli, but also to the intrinsic communication among brain regions, which could have broader implications for phenomena such as emotional reactivity, self-regulation, and perspective taking.

\section{The Dimensional Structure of Political Attitudes}

Consistent with our discussion of left-right ideological differences above, a number of scholars maintain that the spatial metaphor in politics remains "a powerful summary tool" (Campbell, Converse, Miller, \& Stokes, 1960/1965, p. 111) and "provides an economical mode of discourse" (Tedin, 1987, p. 67). In a similar spirit, Jost (2006) opined that "if the left-right distinction did not exist, scholars of ideology would need to invent its equivalent" (p. 130, emphasis omitted). Nevertheless, some authors have argued that two or more independent dimensions are necessary to adequately represent ideological space (e.g., Evans, Heath, \& Lalljee, 1996; Feldman, 2013; Saucier, 2000). According to one proposal, liberalism and conservatism do not signify opposite poles on a continuum but are instead orthogonal ideological dimensions, so that people can (and do) endorse liberal ideas without being opposed to conservative ideas, and vice versa (e.g., see Choma et al., 2009; Conover \& Feldman, 1981; Kerlinger, 1984).

But by far the most common multidimensional scheme focuses on ostensible differences between social (or cultural) and economic attitudes (e.g., Carmines, Ensley, \& Wagner, 2012; Feldman, 2013; Layman \& Carsey, 2002; Lipset, 1960; Shafer \& Claggett, 1995). This distinction is related but not identical to the distinction between resistance to change and acceptance of inequality (Jost et al., 2003). A review of the literature by Jost et al. (2009, pp. 312-315) led to the conclusion that while social and economic dimensions of political orientation are clearly conceptually and empirically distinguishable, it is rare for them to be entirely orthogonal (i.e., uncorrelated) in practice. ${ }^{3}$ It is rarer still for liberal and conservative attitudes to be uncorrelated, especially after adjusting for measurement error.

\section{A Neuroscientific Investigation of a Multidimensional Model of Political Attitudes}

To our knowledge, there has been only one neuroscientific study bearing on the dimensional structure of political attitudes, but it seems like a safe bet that others will follow. Zamboni and colleagues (2009) used a multidimensional (MDS) scaling technique to try to identify fundamentally distinct elements of political opinion. In one phase of the research program, they asked adult

\footnotetext{
${ }^{3}$ It is important to keep in mind that many issues — such as those having to do with welfare programs, affirmative action, and immigration policy-clearly combine both social and economic concerns, and this, too, may help to explain why opinions in the two domains are typically correlated with one another (Jost et al., 2009).
} 
volunteers to read a very long list of political statements and, over the course of several sessions, rate the extent to which each statement was similar to every other statement. Multidimensional scaling procedures yielded three orthogonal dimensions of opinion: (1) whether one emphasizes the role of the individual (e.g., "Everybody should prioritize his or her own interest over society's") or of society (e.g., "Citizens should vote based on collective interest") when it comes to politics; (2) whether one endorses liberal (e.g., "Gays and lesbians should be able to get legally married") or conservative policy attitudes (e.g., "Everybody should oppose teaching evolutionary theory"); and (3) whether one favors moderate (e.g., "The government should protect freedom of speech") as opposed to radical measures (e.g., "People should use violence to pursue political goals"). In a second research phase, the investigators asked a different set of participants (who varied in terms of their own self-identified political orientation) to rate their levels of agreement or disagreement with statements representing each of the three dimensions while their brains were scanned. The idea was to try to isolate the neural correlates of thinking about specific types of political ideas, independent of the participant's own background. ${ }^{4}$

Although this approach was inherently exploratory, Zamboni and colleagues observed some potentially interesting trends. To begin with, the processing of political statements prioritizing individual (vs. societal) concerns was accompanied by activity in the vmPFC, which is a region that is associated with self-reflection (Kelley et al., 2002), as well as more general evaluative processes. By contrast, the processing of statements prioritizing societal concerns was accompanied by activity in the dmPFC, a region that is linked to social cognition and mentalizing about others (Amodio \& Frith, 2006; Mitchell et al., 2002), as well as activity in the temporoparietal junction, a region that is also associated with perspective taking (Samson, Apperly, Chiavarino, \& Humphreys, 2004). Second, the processing of conservative (vs. liberal) statements was associated with greater activity in the right dlPFC, a region that is linked to withdrawal motivation and response inhibition (Aron, Robbins, \& Poldrack, 2004; Davidson, 1992; Harmon-Jones, 2003). Zamboni and colleagues (2009) speculated that this response was attributable to the predominantly liberal character of their sample, but they did not investigate the role of participants' political orientation in moderating neurocognitive responses to political statements. Third, the processing of moderate (vs. radical) statements was accompanied by greater activity in the ventral striatum (as well as the posterior cingulate/precuneus). Given that the ventral striatum is implicated in reward processing (e.g., O'Doherty, 2004), Zamboni and colleagues attributed this pattern to the fact that moderate statements are more socially acceptable (and less emotionally salient) than radical statements. These last effects, in particular, may not be unique to the political domain. One might well predict that processing reasonably moderate (i.e., acceptable, noncontroversial) statements about virtually any topic would activate reward-processing centers, whereas processing extreme (i.e., unacceptable, controversial) statements would activate emotional processing in general.

The take-home message from Zamboni et al. (2009) is that different brain regions were activated when participants ruminated about each of the three different types of statements. The authors interpreted this as evidence for a multidimensional conception of political ideology. Although provocative, the results of this study should probably be treated as preliminary-largely because their methods assumed a multidimensional solution ex ante, and the dimensions they identified were derived on the basis of a purely inductive approach that depended heavily on the specific items that were administered. Nevertheless, we are in full agreement with the authors that cognitive and neuroscientific approaches could be extremely useful for determining whether (and for whom) ideological space is represented in terms of unidimensional vs. multidimensional structural schemes.

\footnotetext{
${ }^{4}$ Zamboni et al. (2009) treated the participant's political orientation as a "nuisance" variable and did not report the results of any statistical models that included interaction terms involving this variable.
} 


\section{Does the Cognitive System Privilege Single, Contrasting Dimensional Schemes?}

Experiments in cognitive psychology reveal that when individuals try to categorize stimuli that differ in terms of two or more underlying dimensions (such as social vs. economic liberalismconservatism) they prefer focusing on a single dimension and using that as the basis for categorization (e.g., Ashby, Queller, \& Berretty, 1999). It stands to reason that imposing a unidimensional structure helps to simplify the decision-making task, especially insofar as people find it much easier to learn and remember unidimensional than multidimensional classification schemes (Shepard, Hovland, \& Jenkins, 1961). Furthermore, Davis and Love (2010) have argued that "human category formation relies on contrastive learning mechanisms" (p. 234) and that contrasts-such as that between the political left and right-may "lead to caricatures that people should find easier to process and more compelling than true categories" (p. 241). In some situations, oversimplification greatly compromises judgmental accuracy (Ashby et al., 1999), but this does not always seem to be the case. Kato and Okada (2011) observed that at least one of the two major dimensions recovered through multidimensional scaling of expert judgments of policy positions was correlated with overall left-right ideological placement in nine of the 13 countries they investigated.

Therefore, one can readily agree that the universe of political issues and opinions can only be represented faithfully in multidimensional space (e.g., Carmines et al., 2012; Feldman, 2013) and yet maintain that actual political actors - for cognitive as well as motivational reasons-might prefer (1) single over multiple dimensions of judgment and (2) contrasting over orthogonal methods of categorization. Consistent with this notion, Heit and Nicholson (2010, p. 1510) observed that when U.S. participants were asked to estimate how liberal and how conservative (in separate questions) a given set of politicians was, the correlation between the two ratings was an astonishing -.97! Contrary to the notion that liberalism and conservatism are mentally represented as orthogonal dimensions (e.g., Choma et al., 2009; Conover \& Feldman, 1981; Kerlinger, 1984), Heit and Nicholson concluded that, subjectively speaking, "Liberal is the opposite of conservative" (p. 1513). An intriguing twist is that different perceivers may develop somewhat different unidimensional rules, depending on which values or characteristics they weight most heavily (e.g., see Benoit \& Laver, 2006, pp. 31-32).

We regard these hypotheses about individuals' cognitive preferences for single and contrasting dimensional schemes as highly deserving of research attention in the future. For instance, computational models that explicate the basic psychological processes underlying human-category formation (e.g., Love, Medin, \& Gureckis, 2004) may help to identify manipulations that promote alternative conceptualizations of political categories (e.g., see Regehr \& Brooks, 1995, for examples involving artificial stimuli). Such modeling efforts may also help to explain why such biases exist in terms of deeper underlying principles involved in the representation of concepts (e.g., Goodwin \& Johnson-Laird, 2011). Finally, neuroscientific investigations of the brain systems involved in category formation may help to determine the extent to which political categories are actually represented in terms of single versus multiple dimensions. For example, multivoxel pattern analyses, when applied to fMRI data, have the potential to reveal patterns of similarity between neural operations implicated in the processing of different category members and may thereby help to elucidate the underlying dimensionality of such representations (e.g., Mitchell et al., 2008; Norman, Polyn, Detre, \& Haxby, 2006).

\section{An Agenda for Future Research in Political Neuroscience}

The application of neuroscientific theories, methods, and assumptions to the study of social psychology has already yielded novel insights and predictions that would have been difficult to develop by relying exclusively on traditional behavioral methods. For instance, our understanding of 
implicit social cognition-especially when it comes to the phenomenon of implicit prejudice and prospects for its regulation or control—has improved dramatically by incorporating neuroscientific advances in research on learning and memory (e.g., Amodio \& Devine, 2006; Amodio \& Ratner, 2011a; Hart et al., 2000; Lieberman, 2000; Phelps et al., 2000). Discoveries in political neuroscience have also begun to challenge traditional assumptions in political science, such as the notion that ordinary citizens' ideological preferences are derived primarily (or even exclusively) through topdown, elite-driven forms of communication that are more or less passively absorbed (see also Hibbing et al., in press; Jost et al., 2009). On the basis of recent work in political neuroscience and behavioral genetics, Smith et al. (2011b) have called for a "reconceptualization" of ideology that is reminiscent of Wilson's (1998) entreaty to unify the natural and social sciences. Specifically, Smith and colleagues argue that "ideology is not a superficial label or bundle of topical positions but rather is a central component of an individual's general life orientations" (p. 378). We share these authors' commitment to the scientific integration of multiple levels of analysis, which incorporates environmental, biological, psychological, social, and political factors.

So far, there are few, if any, instances of research in political neuroscience debunking conclusions drawn on the basis of behavioral studies. In fact, much of the work in political neuroscience has provided convergent evidence for existing theoretical assumptions, which is a necessary and useful step in its own right. The field is still in a fledgling state, and there is much work to be done in refining the concepts and tools in use. At the same time, there is every reason to assume that as methodological sophistication and theoretical precision continue to increase, advances in political neuroscience will corroborate some empirical claims in political psychology while clarifying, qualifying, and supplanting others. For the time being, there is still an abundance of "low-hanging fruit" that is available to investigators. To take just one example, very few studies have explored the neural mechanisms of persuasion despite the obvious centrality of the topic in social psychology, political science, and adjacent fields. Given the importance of propaganda, political advertising, and other forms of communication to political psychology, the opportunities here are virtually unlimited. To balance our enthusiasm for the future of political neuroscience with a dose of realism, we turn now to a consideration of some of the limitations and potential pitfalls of work in this area, offering several additional recommendations with respect to future research.

\section{Limitations of the Brain-Mapping Approach}

As we have seen, the first generation of research in political neuroscience has been largely exploratory, often seeking to determine which brain regions are associated with specific types of political cognition or behavior. The "brain-mapping" approach is intuitively appealing and potentially illuminating, but it is also inherently limited. The initial cohort of studies in political neuroscience is provocative because it already suggests a tentative roster of neurocognitive processes that play some role in phenomena that are central to political psychology (see Table 1 above). At the same time, we have tried to emphasize the fact that conclusions drawn on the basis of brain mapping studies tend to be speculative and subject to multiple explanations (Amodio, 2010a; Poldrack, 2006; Theodoridis \& Nelson, 2012). As Cacioppo and colleagues (2003) have already warned would-be political neuroscientists, "one cannot assume that changes in brain activity are a direct, invariant measure of the neural instantiation of the investigator's favorite construct or that the contemporary neurobiological theory regarding the function of a specific brain structure or system is everlasting" (p. 653).

To take just one example from the many research programs we have summarized, the insula is indeed activated by disgust-inducing images, but the fact remains that it is a fairly large, densely interconnected brain region that is also involved in processes and functions that are entirely unrelated to disgust (Craig, 2009). Therefore, the observation that insula activation tends to occur 
following exposure to a given stimulus by no means entails that people experience disgust when confronted with it. Similarly, regions such as the ACC and PFC are often triggered by tasks that require planned motor responses - that is to say, many, many tasks. This problem is compounded in political neuroscience because most studies do not elicit task-specified actions on behalf of the participant, and yet some kind of behavior is involved (even if it is only viewing candidate images or reporting political attitudes). All of this makes it especially difficult to interpret frontal cortical activations, insofar as such activations could reflect anticipated actions (e.g., voting in the next election) that are not part of the experiment itself. The next generation of studies in political neuroscience, we submit, should make better use of experimental tasks and paradigms that are functionally appropriate for assessing hypotheses about specific patterns of brain activity, and researchers must keep in mind that any mental or physical event (even resting or relaxing) will elicit brain activity of some kind.

At the end of the day, it is impossible to avoid the problem of reverse inference entirely-that is, if one wishes to interpret patterns of brain activation at all. However, it is necessary to treat such interpretations as tentative and subject to revision (Aron et al., 2007; Nature Editorial, 2007; Poldrack, 2006). It should go without saying, perhaps, that any behavior that is as complex and multiply determined as, say, voting for a specific political candidate or participating in a rally or demonstration must be the product of multiple neural systems operating in concert. To establish sound theoretical (and meta-theoretical) foundations for the interpretation of brain-behavior correlations, we propose that the community of political neuroscientists should adhere as scrupulously as possible to a method that we refer to as "collaborative cross-examination" across levels of analysis.

\section{"Collaborative Cross-Examination" of Neural and Behavioral Interpretations}

The best antidote that we can come up with for the problem of reverse inference (and for the pitfalls of the brain-mapping approach more generally) is to adopt an iterative method involving sequential research stages in which interpretations of neural and behavioral processes are crossexamined. The idea is that investigators should use theory and methods at the behavioral level of analysis to check on the validity of interpretations arising from the observation of neural data (and vice versa). For instance, one might begin by hypothesizing that political partisans would exhibit strong negative reactions to the faces of politicians representing an opposing party. This hypothesis would probably lead the researcher to expect an increase in amygdala and/or insula activity following the presentation of prominent political out-group (vs. ingroup) members. Now let us suppose that a given neuroimaging study yields the predicted pattern of insula activation but no evidence of increased amygdala activity. Using reverse inference, the researcher might assume that participants in this situation experienced either disgust or pain-but not fear.

However, because regions such as the insula are implicated in a wide variety of tasks and functions, follow-up research should be designed to formally tease apart these alternative explanations at the level of observable behavior. Feelings of disgust, pain, and fear should be measured or manipulated rather than simply inferred on the basis of patterns of brain activation. In this case, behavioral observations may strengthen the disgust interpretation or call it into question (or suggest additional mediating or moderating variables that might be tested using neuroscientific methods). Over time, this general approach should allow researchers to determine the value of inductive insights made on the basis of reverse inferences from brain activity through the design of behavioral studies to assess specific hypotheses and mechanisms. In this way, researchers proceed iteratively, drawing on (a) behavioral evidence to constrain neuroscientific interpretations and (b) neuroscientific evidence to constrain behavioral interpretations. The result is a decidedly antireductionistic, collaborative approach to science in which psychological and physiological methods and interpretations are regarded as equally indispensable. 


\section{Tackling the "Chicken-and-Egg Problem" in Political Neuroscience}

Through focused testing of process-oriented hypotheses at multiple levels of analysis, the collaborative method of cross-examination may help researchers to move beyond brain-behavior correlations and to finally tackle the "chicken-and-egg problem" in political neuroscience. Jost, Noorbaloochi, and Van Bavel (in press) pointed out that on the basis of existing research it is impossible to know whether, for instance, (1) individual differences in brain structure and function effect outcomes with respect to social and political behavior, and/or (2) the adoption of social and political attitudes and behaviors leads individuals to think in certain ways, causing our brains to process information differently. The most common view is that physiological and psychological characteristics (including personality traits) are heritable, stable, and difficult to change, and so they must shape political dispositions, rather than the other way around (e.g., Hibbing et al., in press; Inbar et al., 2009; Smith et al., 2011b). ${ }^{5}$ This overarching assumption has led some to conclude, quite erroneously, that social and political outcomes (such as racism and political orientation) are "hard-wired."

We suspect that differences in neurocognitive structure and functioning are linked to a constellation of social and psychological processes that unfold over time and both reflect and give rise to the expression of political behavior. In other words, we favor a dynamic, recursive theoretical framework in which the connection between physiological (and psychological) functioning and political outcomes is conceived of as bidirectional rather than unidirectional. Political orientation, we submit, is the product of an "elective affinity" between the discursive, socially constructed elements of ideological belief systems and the psychological constraints, motives, and interests of those who are drawn to those belief systems, so that—as Jost et al. (2009) put it—not only do people choose ideas, but "ideas choose people" (p. 308). Therefore, we are less dismissive than other authors of the possibility that "political attitudes [could] shift a person's general emotional dispositions" (Hibbing et al., in press, p. 27). Indeed, we would hypothesize that certain ideological narratives or frames, if they are consistently encountered and embraced, could indeed affect the individual's psychological and physiological characteristics.

Investigating hypotheses such as this one-and finally beginning to tackle the "chicken-andegg" problem-will require the use of multiple, innovative research methods that make it feasible to isolate causal mechanisms (Jost et al., in press). Some of the most useful methods will be experimental, including the use of Transcranial Magnetic Stimulation (TMS), which involves the local application of small magnetic fields to either activate or deactivate specific cortical regions, thereby enabling investigators to draw causal inferences about the impact of brain structure and function on cognitive and behavioral outcomes. Because TMS relies on relatively weak magnetic fields, however, its application is presently confined to outer cortical regions and cannot be used to isolate structures that are more deeply embedded inside the human brain, such as the amygdala. However, studies involving patients with brain lesions as well as pharmacological interventions-such as the direct administration of neuromodulators - can be used to examine chronic or temporary deficits in subcortical (as well as cortical) regions, and these methods will also help to isolate causal mechanisms and to suggest nonobvious methods of intervention. For instance, Terbeck et al. (2012) reported that a dose of propranolol (a beta-blocker medication that dampens amygdala activity) led to a significant reduction in implicit racial bias. Given existing research in political psychology, one cannot help but wonder if this intervention would also increase participants' affinities for liberal or progressive ideas and opinions (e.g., see Oxley et al., 2008; Thorisdottir \& Jost, 2011).

Prospective, longitudinal methods have much to offer as well (cf. Block \& Block, 2006; Fraley et al., 2012; Matthews et al., 2009)—especially if researchers are able to monitor changes in brain

\footnotetext{
${ }^{5}$ According to a quite different, more speculative view about human genetics, the relationship between personality and political outcomes is itself spurious (Verhulst, Eaves, \& Hatemi, 2012).
} 
structure and activity over time as a function of intervening experiences. Studies of nonhuman animals have demonstrated that the brain can change quite drastically in response to training and experience (e.g., Fu \& Zuo, 2011), and, increasingly, it would appear that this is true of human animals as well. For instance, compassion training alters neural responses in the anterior cingulate and anterior insula - brain regions that are associated with empathy in response to the pain of others (Klimecki, Leiberg, Ricard, \& Singer, 2013).

In terms of structural changes, men who complete a four-year training program to become London taxi drivers exhibited increased grey-matter volume in the posterior hippocampus, along with significant changes in memory capacity (Woollett \& Maguire, 2011). Although there are limitations to what can be concluded on the basis of existing research (see Thomas \& Baker, 2012), some changes in brain structure have been observed following training in a variety of domains, including exercise (Erickson et al., 2011), academic instruction (Ceccarelli et al., 2009), second-language acquisition (Mechelli et al., 2004), musical training (Hyde et al., 2009), golfing (Bezzola, Mérillat, Gaser, \& Jäncke, 2011), and juggling (Boyke, Driemeyer, Gaser, Büchel, \& May, 2008; Draganski et al., 2004). Of course, at this point one can only guess about the neurological consequences of watching Fox News or PBS Newshour for years at a time, but evidence from cognitive neuroscience suggests that repeated experiences may be capable of altering the structures and functions of the human brain.

\section{Concluding Remarks}

These are early days, to be sure, for the study of political neuroscience. At the same time, there is already enough theoretical, methodological, and empirical convergence to be enthusiastic about prospects for future research. We find ourselves in hearty agreement with Taber and Young (2013), who declared that: "The explosion of findings in automaticity and brain-imaging research relevant to opinion formation represents a strong step in the direction of explaining what we believe with how we think" (p. 549, emphasis added). This description aptly characterizes research on all four of the key topics that we have focused on this chapter, namely: (1) the role of the amygdala in racial perception, categorization, and bias, and the role of the AACC and IPFC in detecting and overriding intergroup bias; (2) the role of the amygdala, insula, and ventral striatum in encoding partisan preferences and responding to political out-group members; (3) the nature of left-right (or liberal-conservative) differences in political orientation and how these differences might manifest themselves in terms of brain structure and function, especially when it comes to the ACC, amygdala, and insula; and (4) the dimensional structure of political attitudes and the extent to which research in cognitive neuroscience can shed light on the question of whether individuals might harbor preferences for single and contrasting dimensional schemes (such as the left-right dimension). It would be virtually impossible to predict the major themes of research that are likely to take hold in political neuroscience over the next decade or two. From our point of view, this unpredictability is something to savor and perhaps to celebrate, insofar as the scientific method is most powerful when it is used for something more than peering around the next corner. Perhaps those who like to know what is foreseeable, however, can take some solace from this most sanguine of predictions: There will be far more and, in all likelihood, far more revealing studies carried out in political neuroscience in the years to come.

\section{ACKNOWLEDGMENTS}

Some of the research described herein was funded by New York University, including grants from the Center for Brain Imaging. We are grateful to Lisa Kaggen for assistance with the preparation of tables, figures, and references. Thanks to Todd Gureckis, Leor Hackel, Howard Lavine, Gregory Murphy, Sharareh Noorbaloochi, Joanna Sterling, Chadly Stern, and Jenny Xiao for helpful comments and advice with respect to earlier versions and specific subsections. Correspondence concerning this 
article should be sent to John T. Jost, Department of Psychology, New York University, 6 Washington Place, 5th Floor, New York, NY 10003. E-mail: john.jost@ nyu.edu

\section{REFERENCES}

Adolphs, R. (2009). The social brain: Neural basis of social knowledge. Annual Review of Psychology, 60, 693-716.

Adorno, T. W., Frenkel-Brunswik, E., Levinson, D. J., \& Sanford, R. N. (1950). The authoritarian personality. New York, NY: Harper.

Alford, J. R., \& Hibbing, J. R. (2008). The new empirical biopolitics. Annual Review of Political Science, 11, $183-203$.

Allport, G. W. (1954). The nature of prejudice. Reading, MA: Addison-Wesley.

Amodio, D. M. (2008). The social neuroscience of intergroup relations. European Review of Social Psychology, $19,1-54$.

Amodio, D. M. (2010a). Can neuroscience advance social psychological theory? Social neuroscience for the behavioral social psychologist. Social Cognition, 28, 695-716.

Amodio, D. M. (2010b). Coordinated roles of motivation and perception in the regulation of intergroup responses: Frontal cortical asymmetry effects on the P2 event-related potential and behavior. Journal of Cognitive Neuroscience, 22, 2609-2617.

Amodio, D. M., \& Devine, P. G. (2006). Stereotyping and evaluation in implicit race bias: Evidence for independent constructs and unique effects on behavior. Journal of Personality and Social Psychology, 91, 652-661.

Amodio, D. M., Devine, P. G., \& Harmon-Jones, E. (2007). A dynamic model of guilt: Implications for motivation and self-regulation in the context of prejudice. Psychological Science, 18, 524-530.

Amodio, D. M., Devine, P. G., \& Harmon-Jones, E. (2008). Individual differences in the regulation of intergroup bias: The role of conflict monitoring and neural signals for control. Journal of Personality and Social Psychology, 94, 60-74.

Amodio, D. M., \& Frith, C. D. (2006). Meeting of minds: The medial frontal cortex and social cognition. Nature Reviews Neuroscience, 7, 268-277.

Amodio, D. M., \& Hamilton, H. K. (2012). Intergroup anxiety effects on implicit racial evaluation and stereotyping. Emotion, $12,1273-1280$.

Amodio, D. M., Harmon-Jones, E., \& Devine, P. G. (2003). Individual differences in the activation and control of affective race bias as assessed by startle eyeblink responses and self-report. Journal of Personality and Social Psychology, 84, 738-753.

Amodio, D. M., Harmon-Jones, E., Devine, P. G., Curtin, J. J., Hartley, S. L., \& Covert, A. E. (2004). Neural signals for the detection of unintentional race bias. Psychological Science, 15, 88-93.

Amodio, D. M., Jost, J. T., Master, S. L., \& Yee, C. M. (2007). Neurocognitive correlates of liberalism and conservatism. Nature Neuroscience, 10, 1246-1247.

Amodio, D. M., Kubota, J. T., Harmon-Jones, E., \& Devine, P. G. (2006). Alternative mechanisms for regulating racial responses according to internal vs. external cues. Social Cognitive and Affective Neuroscience, 1, 26-36.

Amodio, D. M., \& Ratner, K. G. (2011a). A memory systems model of implicit social cognition. Current Directions in Psychological Science, 20, 143-148.

Amodio, D. M., \& Ratner, K. G. (2011b). Mechanisms for the regulation of intergroup responses: A social neuroscience analysis. In J. Decety \& J. T. Cacioppo (Eds.), Handbook of social neuroscience (pp. 729-741). New York, NY: Oxford University Press.

Anders, S., Lotze, M., Erb, M., Grodd, W., \& Birbaumer, N. (2004). Brain activity underlying emotional valence and arousal: A response-related fMRI study. Human Brain Mapping, 23, 200-209.

Anderson, A. K., \& Phelps, E. A. (2001). Lesions of the human amygdala impair enhanced perception of emotionally salient events. Nature, 411, 305-309.

Aron, A., Badre, D., Brett, M., Cacioppo, J., Chambers, C., Cools, R., Engel, S., D’Esposito, M., Frith, C., Harmon-Jones, E., Jonides, J., Knutson, B., Phelps, E. A., Poldrack, R., Wager, T., Wagner, A., \& Winkielman, P. (2007, November 14). Letter: Politics and the brain. New York Times. http://query.nytimes.com/gst/fullpage.html?res =9907E1D91E3CF937A25752C1A9619C8B63

Aron, A., Robbins, T. W., \& Poldrack, R. A. (2004). Inhibition and the right inferior frontal cortex. Trends in Cognitive Sciences, 8, 170-177.

Ashby, F. G., Queller, S., \& Berretty, P. M. (1999). On the dominance of unidimensional rules in unsupervised categorization. Perception \& Psychophysics, 61, 1178-1199.

Aspelund, A., Lindeman, M., \& Verkasalo, M. (2013). Political conservatism and left-right orientation in 28 Eastern and Western European countries. Political Psychology, 34, 409-417. 
Baliki, M. N., Geha, P. Y., \& Apkarian, A. V. (2009). Parsing pain perception between nocioceptive representation and magnitude estimation. Journal of Neurophysiology, 101, 875-887.

Bartholow, B. D., \& Amodio, D. M. (2009). Using event-related brain potentials in social psychological research: A brief review and tutorial. In E. Harmon-Jones \& J. Beer (Eds.), Methods in social neuroscience (pp. 198-232). New York, NY: Guilford.

Bartholow, B. D., Dickter, C. L., \& Sestir, M. A. (2006). Stereotype activation and control of race bias: Cognitive control of inhibition and its impairment by alcohol. Journal of Personality and Social Psychology, 90, 272-287.

Bartholow, B. D., Fabiani, M., Gratton, G., \& Bettencourt, B. A. (2001). A psychophysiological analysis of cognitive processing of and affective responses to social expectancy violations. Psychological Science, 12, 197-204.

Bartholow, B. D., Pearson, M.A., Gratton, G., \& Fabiani, M. (2003). Effects of alcohol on person perception: A social cognitive neuroscience approach. Journal of Personality and Social Psychology, 85, 627-638.

Beer, J. S., Stallen, M., Lombardo, M. V., Gonsalkorale, K., Cunningham, W. A., \& Sherman, J. W. (2008). The quadruple process model approach to examining the neural underpinnings of prejudice. NeuroImage, 43, 775-783.

Benoit, K., \& Laver, M. (2006). Party policy in modern democracies. London, UK: Routledge.

Bezzola, L., Mérillat, S., Gaser, C., \& Jäncke, L. (2011). Training-induced neural plasticity in golf novices. The Journal of Neuroscience, 31, 12444-12448.

Block, J., \& Block, J. J. (2006). Nursery school personality and political orientation two decades later. Journal of Research in Personality, 40, 734-749.

Bodenhausen, G. V., \& Macrae, C. N. (1998). Stereotype activation and inhibition. In R.S. Wyer Jr. (Ed.), Stereotype activation and inhibition (pp. 1-52). Mahwah, NJ: Erlbaum.

Bonanno, G. A., \& Jost, J. T. (2006). Conservative shift among high-exposure survivors of the September 11th terrorist attacks. Basic and Applied Social Psychology, 28, 311-323.

Botvinick, M. M., Braver, T. S., Barch, D. M., Carter, C. S., \& Cohen, J. D. (2001). Conflict monitoring and cognitive control. Psychological Review, 108, 624-652.

Bouton, M. E. (1994). Conditioning, remembering, and forgetting. Journal of Experimental Psychology: Animal Behavior Processes, 20, 219-231.

Boyke, J., Driemeyer, J., Gaser, C., Büchel, C., \& May, A. (2008). Training-induced brain structure changes in the elderly. Journal of Neuroscience, 28, 7031-7035.

Bradley, M. M., Cuthbert, B. N., \& Lang, P. J. (1990). Startle reflex modification: Emotion or attention? Psychophysiology, 27, 513-522.

Brewer, M. B. (1988). A dual process model of impression formation. In R. Wyer \& T. Srull (Eds.), Advances in social cognition (Vol. 1, pp. 1-36). Hillsdale, NJ: Erlbaum.

Brosch, T., Bar-David, E., \& Phelps, E. A. (2013). Implicit race bias decreases the similarity of neural representations of black and white faces. Psychological Science, 24, 160-166.

Burke, B. L., Kosloff, S., \& Landau, M. J. (2013). Death goes to the polls: A meta-analysis of mortality salience effects on political attitudes. Political Psychology, 34, 183-200.

Cacioppo, J. T., \& Berntson, G. G. (1992). Social psychological contributions to the decade of the brain: Doctrine of multilevel analysis. American Psychologist, 47, 1019-1028.

Cacioppo, J. T., Berntson, G. G., Lorig, T. S., Norris, C. J., Rickett, E., \& Nusbaum, H. (2003). Just because you're imaging the brain doesn't mean you can stop using your head: A primer and set of first principles. Journal of Personality and Social Psychology, 85, 650-661.

Cacioppo, J. T., \& Visser, P. S. (2003). Political psychology and social neuroscience: Strange bedfellows or comrades in arms? Political Psychology, 24, 647-656.

Caldara, R., Thut, G., Servoir, P., Michel, C., Bovet, P., \& Renault, B. (2003). Face versus non-face object perception and the other-race effect: A spatio-temporal event-related potential study. Clinical Neurophysiology, 114, 515-528.

Campbell, A., Converse, P., Miller, W., \& Stokes, D. (1960/1965). The American voter. Chicago, IL: Wiley.

Carmen, I. H. (2007). Genetic configurations of political phenomena: New theories, new methods. The ANNALS of the American Academy of Political and Social Science, 614, 34-55.

Carmines, E. G., Ensley, M. J., \& Wagner, M. W. (2012). Who fits the left-right divide? Partisan polarization in the American electorate. American Behavioral Scientist, 56, 1631-1653.

Carney, D. R., Jost, J. T., Gosling, S. D., \& Potter, J. (2008). The secret lives of liberals and conservatives: Personality profiles, interaction styles, and the things they leave behind. Political Psychology, 29, 807-840.

Carraro, L., Castelli, L., \& Macchiella, C. (2011). The automatic conservative: Ideology-based attentional asymmetries in the processing of valenced information. PLOS ONE, 6(11): e26456. doi:10.1371/journal.pone.0026456

Carter, C. S., Braver, T. S., Barch, D. M., Botvinick, M. M., Noll, D., \& Cohen, J. D. (1998). Anterior cingulate cortex, error detection, and the online monitoring of performance. Science, 280, 747-749. 
Ceccarelli, A., Rocca, M. A., Pagani, E., Falini, A., Comi, G., \& Filippi, M. (2009). Cognitive learning is associated with gray matter changes in healthy human individuals: A tensor-based morphometry study. Neuroimage, 48, 585589.

Chambers, J. R., Schlenker, B. R., \& Collisson, B. (2013). Ideology and prejudice: The role of value conflicts. Psychological Science, 24, 140-149.

Chirumbolo, A., Areni, A., \& Sensales, G. (2004). Need for cognitive closure and politics: Voting, political attitudes, and attributional style. International Journal of Psychology, 39, 245-253.

Choma, B. L., Busseri, M. A., \& Sadava, S. W. (2009). Liberal and conservative political ideologies: Different routes to happiness? Journal of Research in Personality, 43, 502-505.

Cichocka, A., \& Jost, J. T. (2013). Stripped of illusions? Exploring system justification processes in Capitalist and postCommunist societies. International Journal of Psychology.

Cikara, M., Bruneau, E. G., \& Saxe, R. (2011). Us and them: Intergroup failures of empathy. Current Directions in Psychological Science, 20, 149-153.

Cloutier, J., Gabrieli, J. D., O’Young, D., \& Ambady, N. (2011). An fMRI study of violations of social expectation: When people are not who we expect them to be. Neuroimage, 57, 583-588.

Cohen, G. L. (2003). Party over policy: The dominating impact of group influence on political beliefs. Journal of Personality and Social Psychology, 85, 808-822.

Conover, P. J., \& Feldman, S. (1981). The origin and meaning of liberal/conservative self-identification. American Journal of Political Science, 25, 617-645.

Cooper, J. B., \& Siegel, H. E. (1956). The galvanic skin response as a measure of emotion in prejudice. Journal of Psychology, $42,149-155$.

Cooper, J. B., \& Singer, D. N. (1956). The role of emotion in prejudice. Journal of Social Psychology, 44, 241-247.

Cox, C. L., Jost, J. T., Castellanos, F. X., Milham, M. P., Kelly, C., \& Van Bavel, J. J. (2012, April). Individual differences in political orientation are reflected in the intrinsic functional organization of the human brain. Poster presented at the $5^{\text {th }}$ Annual Meeting of the Social and Affective Neuroscience Society, New York, NY.

Craig, A. D. (2009). How do you feel—now? The anterior insula and human awareness. Nature Reviews Neuroscience, 10, 59-70.

Critcher, C. R., Huber, M., Ho, A. K., \& Koleva, S. P. (2009). Political orientation and ideological inconsistencies: (Dis)comfort with value tradeoffs. Social Justice Research, 22, 181-205.

Cunningham, W. A., Johnson, M. K., Raye, C. L., Gatenby, J. C., Gore, J. C., \& Banaji, M. R. (2004). Separable neural components in the processing of black and white faces. Psychological Science, 15, 806-813.

Cunningham, W. A., \& Van Bavel, J. J. (2009). A neural analysis of intergroup perception and evaluation. In G.G. Berntson \& J. T. Cacioppo (Eds.), Handbook of neuroscience for the behavioral sciences (Vol. 1, pp. 975-984). Hoboken, NJ: John Wiley \& Sons.

Cunningham, W. A., Van Bavel, J. J., \& Johnsen, I. R. (2008). Affective flexibility: Evaluative processing goals shape amygdala activity. Psychological Science, 19, 152-160.

Davidson, R. J. (1992). Anxiety and affective style: Role of prefrontal cortex and amygdala. Biological Psychiatry, 51, 68-80.

Davis, M. (1992). The role of the amygdala in fear and anxiety. Annual Review of Neuroscience, 15, 353-375.

Davis, M. (2006). Neural systems involved in fear and anxiety measured with fear-potentiated startle. American Psychologist, $61,741-756$.

Davis, T., \& Love, B. C. (2010). Memory for category information is idealized through contrast with competing options. Psychological Science, 21, 234-242.

Dennis, T., Jost, J. T., Amodio, D., O’Toole, L., \& Medina, A. (2013). Family ties? Effects of parental ideology on neural sensitivity to cognitive conflict in children. Manuscript submitted for publication.

Derks, B., Scheepers, D., \& Ellemers, N. (Eds.), (2013). Neuroscience of prejudice and intergroup relations. London, UK: Psychology Press.

Devine, P. G. (1989). Stereotypes and prejudice: Their automatic and controlled components. Journal of Personality and Social Psychology, 56, 5-18.

Devine, P. G., Plant, E. A., Amodio, D. M., Harmon-Jones, E., \& Vance, S. L. (2002). The regulation of explicit and implicit race bias: The role of motivations to respond without prejudice. Journal of Personality and Social Psychology, 82, 835-848.

Dollinger, S. J. (2007). Creativity and conservatism. Personality and Individual Differences, 43, 1025-1035.

Dovidio, J. F., Hebl, M., Richeson, J. A, \& Shelton, J. N. (2006). Nonverbal communication, race, and intergroup interaction. In V. Manusov \& M. L. Patterson (Eds.), The Sage handbook of nonverbal communication (pp. 481-500). Thousand Oaks, CA: Sage. 
Dovidio, J. F., Kawakami, K., Johnson, C., Johnson, B., \& Howard, A. (1997). On the nature of prejudice: Automatic and controlled processes. Journal of Experimental Social Psychology, 33, 510-540.

Draganski, B., Gaser, C., Busch, V., Schuierer, G., Bogdahn, U., \& May, A. (2004). Changes in grey matter induced by training. Nature, 427, 311-312.

Eidelman, S., Crandall, C. S., Goodman, J. A., \& Blanchar, J. C. (2012). Low-effort thought promotes political conservatism. Personality and Social Psychology Bulletin, 38, 808-820.

Erickson, K. I., Voss, M. W., Prakash, R. S., Basak, C., Szabo, A., Chaddock, L., Kim, J. S., Heo, S., Alves, H., \& White, S. M. (2011). Exercise training increases size of hippocampus and improves memory. Proceedings of the National Academy of Sciences, 108, 3017-3022.

Erikson, R. S., Luttbeg, N. R., \& Tedin, K. L. (1988). American public opinion: Its origins, content, and impact. New York, NY: Macmillan.

Evans, G., Heath, A., \& Lalljee, M. (1996). Measuring left-right and libertarian-authoritarian values in the British electorate. The British Journal of Sociology, 47, 93-112.

Fazio, R. H. (1990). Multiple processes by which attitudes guide behavior: The MODE model as an integrative framework. In M. P. Zanna (Ed.), Advances in experimental social psychology (Vol. 23, pp. 75-109). New York, NY: Academic Press.

Fazio, R. H., Jackson, J. R., Dunton, B. C., \& Williams, C. J. (1995). Variability in automatic activation as an unobtrusive measure of racial attitudes: A bona fide pipeline? Journal of Personality and Social Psychology, 69, 1013-1027.

Federico, C. M., Ergun, D., \& Hunt, C. V. (2013). Opposition to equality and support for tradition as mediators of the relationship between epistemic motivation and system justification. Manuscript submitted for publication.

Federico, C. M., \& Goren, P. (2009). Motivated social cognition and ideology: Is attention to elite discourse a prerequisite for epistemically motivated political affinities? In J. T. Jost, A. C. Kay, \& H. Thorisdottir (Eds.), Social and psychological bases of ideology and system justification (pp. 267-291). New York, NY: Oxford University Press.

Feldman, S. (2013). Political ideology. In L. Huddy, D. O. Sears, \& J. S. Levy (Eds.), The Oxford handbook of political psychology ( $2^{\text {nd }}$ ed., pp. 591-626). New York, NY: Oxford.

Fendt, M., \& Fanselow, M. S. (1999). The neuroanatomical and neurochemical basis of conditioned fear. Neuroscience and Biobehavioral Reviews, 23, 743-760.

Fiske, S. T., \& Neuberg, S. L. (1990). A continuum model of impression formation, from category-based to individuating processes: Influence of information and motivation on attention and interpretation. In M. P. Zanna (Ed.), Advances in experimental social psychology (Vol. 23, pp. 1-74). New York, NY: Academic Press.

Fowler, J. H., \& Schreiber, D. (2008). Biology, politics, and the emerging science of human nature. Science, 302, 912914.

Fraley, R. C., Griffin, B. N., Belsky, J., \& Roisman, G. I. (2012). Developmental antecedents of political ideology: A longitudinal investigation from birth to age 18 years. Psychological Science, 23, 1425-1431.

Fu, M., \& Zuo, Y. (2011). Experience-dependent structural plasticity in the cortex. Trends in Neurosciences, 34, 177187.

Fuchs, D., \& Klingemann, H.-D. (1990). The left-right schema. In M. K. Jennings, J. W. van Deth, et al. (Eds.), Continuities in political action: A longitudinal study of political orientations in three Western democracies (pp. 203-234). New York, NY: Walter de Gruyter.

Gabrieli, J. D. E. (1998). Cognitive neuroscience of human memory. Annual Review of Psychology, 49, 87-115.

Gallagher, M., \& Chiba, A. (1996). The amygdala and emotion. Current Opinion in Neurobiology, 6, $221-227$.

Galvan, A., Hare, T. A., Davidson, M., Spicer, J., Glover, G., \& Casey, B. J. (2005). The role of ventral frontostriatal circuitry in reward-based learning in humans. Journal of Neuroscience, 25, 8650-8656.

Garrett, R. K. (2009). Politically motivated reinforcement seeking: Reframing the selective exposure debate. Journal of Communication, 59, 676-699.

Gehring, W. J., Goss, B., Coles, M. G. H., Meyer, D. E., \& Donchin, E. (1993). A neural system for error detection and compensation. Psychological Science, 4, 385-390.

Gerber, A. S., Huber, G. A., Doherty, D., \& Dowling, C. M. (2010). Personality and political attitudes: Relationships across issue domains and political contexts. American Political Science Review, 104, 111-133.

Gilbert, S. J., Swencionis, J. K., \& Amodio, D. M. (2012). Evaluative vs. trait representation in intergroup social judgments: Distinct roles of anterior temporal lobe and prefrontal cortex. Neuropsychologia, 50, 3600-3611.

Golby, A. J., Gabrieli, J. D. E., Chiao, J. Y., \& Eberhardt, J. L. (2001). Differential responses in the fusiform region to same-race and other-race faces. Nature Neuroscience, 4, 845-850.

Golec de Zavala, A., \& van Bergh, A. (2007). Need for cognitive closure and conservative political beliefs: Differential mediation by personal worldviews. Political Psychology, 28, 587-609. 
Gonsalkorale, K., Sherman, J. W., Allen, T. J., Klauer, K. C., \& Amodio, D. M. (2011). Accounting for successful control of implicit racial bias: The roles of association activation, response monitoring, and overcoming bias. Personality and Social Psychology Bulletin, 37, 1534-1545.

Goodwin, G. P., \& Johnson-Laird, P. N. (2011). Mental models of Boolean concepts. Cognitive Psychology, 63, 34-59.

Gozzi, M., Zamboni, G., Krueger, F., \& Grafman, J. (2010). Interest in politics modulates neural activity in the amygdala and ventral striatum. Human Brain Mapping, 31, 1763-1771.

Guglielmi, R. S. (1999). Psychophysiological assessment of prejudice: Past research, current status, and future directions. Personality and Social Psychology Review, 3, 123-157.

Halberstadt, J., Sherman, S. J., \& Sherman, J. W. (2011). Why Barack Obama is black: A cognitive account of hypodescent. Psychological Science, 22, 29-33.

Hamilton, D. L., Driscoll, D. M., \& Worth, L. T. (1989). Cognitive organization of impressions: Effects of incongruency in complex representations. Journal of Personality and Social Psychology, 57, 925-939.

Harmon-Jones, E. (2003). Clarifying the emotive functions of asymmetrical frontal cortical activity. Psychophysiology, 40, 838-848.

Hart, A. J., Whalen, P. J., Shin, L. M., McInerney, S. C., Fischer, H., \& Rauch, S. L. (2000). Differential response in the human amygdala to racial outgroup vs. ingroup face stimuli. NeuroReport, 11, 2351-2355.

Hastie, R., \& Kumar, P. A. (1979). Person memory: Personality traits as organizing principles in memory for behaviors. Journal of Personality and Social Psychology, 37, 25-38.

Haxby, J. V., Hoffman, E. A., \& Gobbini, M. I. (2000). The distributed human neural system for face perception. Trends in Cognitive Sciences, 4, 223-233.

Hein, G., Silani, G., Preuschoff, K., Batson, C. D., \& Singer, T. (2010). Neural responses to ingroup and outgroup members' suffering predict individual differences in costly helping. Neuron, 68, 149-160.

Heit, E., \& Nicholson, S. P. (2010). The opposite of Republican: Polarization and political categorization. Cognitive Science, 34, 1503-1516.

Helzer, E., \& Pizarro, D. A. (2011). Dirty liberals! Reminders of cleanliness promote conservative political and moral attitudes. Psychological Science, 22, 517-522.

Hennes, E. P., Nam, H. H., Stern, C., \& Jost, J. T. (2012). Not all ideologies are created equal: Epistemic, existential, and relational needs predict system-justifying attitudes. Social Cognition, 30, 669-688.

Hertz, R. (1909). The preeminence of the right hand: A study in religious polarity. In R. Needham (Ed.), Death and the right hand (pp. 89-160). London: Cohen \& West.

Hess, U. (2009). Facial EMG. In E. Harmon-Jones \& J. S. Beer (Eds.), Methods in social neuroscience (pp. 70-91). New York, NY: Guilford Press.

Hibbing, J. R., Smith, K. B., \& Alford, J. R. (in press). Differences in negativity bias underlie variations in political ideology. Behavioral and Brain Sciences.

Hirsh, J. B., DeYoung, C. G., Xu, X., \& Peterson, J. B. (2010). Compassionate liberals and polite conservatives: Associations of agreeableness with political ideology and moral values. Personality and Social Psychology Bulletin, 36, 655-664.

Ho, A. K., Sidanius, J., Levin, D. T., \& Banaji, M. R. (2011). Evidence for hypodescent and racial hierarchy in the categorization and perception of biracial individuals. Journal of Personality and Social Psychology, 100, $492-506$.

Holland, P. C., \& Gallagher, M. (1999). Amygdala circuitry in attentional and representational processes. Trends in Cognitive Sciences, 3, 65-73.

Huddy, L., Sears, D. O., \& Levy, J. (2013). Introduction: Theoretical foundations of political psychology. In L. Huddy, D. O. Sears, \& J. Levy (Eds.), The Oxford handbook of political psychology (2 ${ }^{\text {nd }}$ ed., pp. 1-19). New York, NY: Oxford University Press.

Hyde, K. L., Lerch, J., Norton, A., Forgeard, M., Winner, E., Evans, A. C., \& Schlaug, G. (2009). Musical training shapes structural brain development. Journal of Neuroscience, 29, 3019-3025.

Inbar, Y., Pizarro, D. A., \& Bloom, P. (2009). Conservatives are more easily disgusted than liberals. Cognition and Emotion, 23, 714-725.

Inbar, Y., Pizarro, D. A., Knobe, J., \& Bloom, P. (2009). Disgust sensitivity predicts intuitive disapproval of gays. Emotion, 9, 435-439.

Inglehart, R. (1989). Culture shift in advanced industrial society. Princeton, NJ: Princeton University Press.

Inzlicht, M., McGregor, I., Hirsh, J. B., \& Nash, K. (2009). Neural markers of religious conviction. Psychological Science, 20, 385-392.

Ito, T. A., \& Bartholow, B. D. (2009). The neural correlates of race. Trends in Cognitive Sciences, 13, 524-531.

Ito, T. A., \& Cacioppo, J. T. (2000). Electrophysiological evidence of implicit and explicit categorization processes. Journal of Experimental Social Psychology, 35, 660-676. 
Ito, T. A., \& Urland, G. R. (2003). Race and gender on the brain: Electrocortical measures of attention to the race and gender of multiply categorizable individuals. Journal of Personality and Social Psychology, 85, 616-626.

Iyengar, S., Hahn, K. S., Krosnick, J. A., \& Walker, J. (2008). Selective exposure to campaign communication: The role of anticipated agreement and issue public membership. Journal of Politics, 70, 186-200.

Jost, J. T. (2006). The end of the end of ideology. American Psychologist, 61, 651-670.

Jost, J. T. (2009). "Elective affinities": On the psychological bases of left-right differences. Psychological Inquiry, 20, $129-141$.

Jost, J. T., \& Amodio, D. M. (2012). Political ideology as motivated social cognition: Behavioral and neuroscientific evidence. Motivation and Emotion, 36, 55-64.

Jost, J. T., Federico, C. M., \& Napier, J. L. (2009). Political ideology: Its structure, functions, and elective affinities. Annual Review of Psychology, 60, 307-333.

Jost, J. T., Federico, C. M., \& Napier, J. L. (2013). Political ideologies and their social psychological functions. In M. Freeden, L.T. Sargent, \& M. Stears (Eds.), The Oxford handbook of political ideologies (pp. 232-250). New York, NY: Oxford University Press.

Jost, J. T., Glaser, J., Kruglanski, A.W., \& Sulloway, F. (2003). Political conservatism as motivated social cognition. Psychological Bulletin, 129, 339-375.

Jost, J. T., \& Hardin, C. D. (2011). On the structure and dynamics of human thought: The legacy of William J. McGuire for social and political psychology. Political Psychology, 32, 21-57.

Jost, J. T., Hennes, E. P., \& Lavine, H. (2013). Hot political cognition: Its self-, group, and system-serving purposes. In D. Carlston (Ed.), Oxford handbook of social cognition (pp. 851-875). New York, NY: Oxford University Press.

Jost, J. T., Napier, J. L., Thorisdottir, H., Gosling, S. D., Palfai, T. P., \& Ostafin, B. (2007). Are needs to manage uncertainty and threat associated with political conservatism or ideological extremity? Personality and Social Psychology Bulletin, 33, 989-1007.

Jost, J. T., Noorbaloochi, S., \& Van Bavel, J. J. (in press). The chicken-and-egg problem in political neuroscience. Behavioral and Brain Sciences.

Jost, J. T., Nosek, B. A., \& Gosling, S. D. (2008). Ideology: Its resurgence in social, personality, and political psychology. Perspectives on Psychological Science, 3, 126-136.

Jost, J. T., Rudman, L. A., Blair, I. V., Carney, D., Dasgupta, N., Glaser, J., \& Hardin, C. D. (2009). The existence of implicit bias is beyond reasonable doubt: A refutation of ideological and methodological objections and executive summary of ten studies that no manager should ignore. Research in Organizational Behavior, 29, 39-69.

Jost, J. T., \& Sidanius, J. (Eds.), (2004). Political psychology: Key readings. New York, NY: Psychology Press/Taylor \& Francis.

Jost, J. T., West, T. V., \& Gosling, S. D. (2009). Personality and ideology as determinants of candidate preferences and Obama conversion in the 2008 U.S. presidential election. Dubois Review: Social Science on Race, 6, 103-124.

Kanai, R., Feilden, T., Firth, D., \& Rees, G. (2011). Political orientations are correlated with brain structure in young adults. Current Biology, 21, 677-680.

Kandler, C., Bleidorn, W., \& Riemann, R. (2012). Left or right? Sources of political orientation: The roles of genetic factors, cultural transmission, assortative mating, and personality. Journal of Personality and Social Psychology, 102, 633-645.

Kanwisher, N., McDermott, J., \& Chun, M. M. (1997). The fusiform face area: A module in human extrastriate cortex specialized for face perception. Journal of Neuroscience, 17, 4302-4311.

Kaplan, J. T., Freedman, J., \& Iacoboni, M. (2007). Us versus them: Political attitudes and party affiliation influence neural response to faces of presidential candidates. Neuropsychologia, 45, 55-64.

Kato, J., Ide, H., Kabashima, I., Kadota, H., Takano, K., \& Kansaku, K. (2009). Neural correlates of attitude change following positive and negative advertisements. Frontiers in Behavioral Neuroscience, 3, 1-13. doi:10.3389/neuro.08.006.2009

Kato, J., \& Okada, K. (2011). Simplification and shift in cognition of political difference: Applying the geometric modeling to the analysis of semantic similarity judgment. PLOS ONE, 6(6): e20693. doi:10.1371/journal.pone.0020693

Kaul, C., Ratner, K. G., \& Van Bavel, J. J. (2013). Dynamic representations of race: Processing goals shape race decoding in the fusiform gyri. Social Cognitive and Affective Neuroscience. doi:10.1093/scan/nss 138

Kay, A. C., Gaucher, D., Napier, J. L., Callan, M. J., \& Laurin, K. (2008). God and the government: Testing a compensatory control mechanism for the support of external systems. Journal of Personality and Social Psychology, 95, 18-35.

Kay, A. C., Gaucher, D., Peach, J. M., Laurin, K., Friesen, J., Zanna, M. P., \& Spencer, S. J. (2009). Inequality, discrimination, and the power of the status quo: Direct evidence for a motivation to see the way things are as they way they should be. Journal of Personality and Social Psychology, 97, 421-434. 
Keller, J. (2005). In genes we trust: The biological component of psychological essentialism and its relationship to mechanisms of motivated social cognition. Journal of Personality and Social Psychology, 88, 686-702.

Kelley, W. M., Macrae, C. N., Wyland, C. L., Caglar, S., Inati, S., \& Heatherton, T. F. (2002). Finding the self? An event-related fMRI study. Journal of Cognitive Neuroscience, 14, 785-794.

Kemmelmeier, M. (2007). Political conservatism, rigidity, and dogmatism in American foreign policy officials: The 1966 Mennis data. Journal of Psychology, 141, 77-90.

Kerlinger, F. M. (1984). Liberalism and conservatism: The nature and structure of social attitudes. Hillsdale, NJ: Erlbaum.

Klimecki, O. M., Leiberg, S., Ricard, M., \& Singer, T. (2013). Differential pattern of functional brain plasticity after compassion and empathy training. Social Cognitive and Affective Neuroscience. doi:10.1093/scan/nst060

Knutson, K. M., Wood, J. N., Spampinato, M. V., \& Grafman, J. (2006). Politics on the brain: An fMRI investigation. Social Neuroscience, 1, 25-40.

Krendl, A. C., Macrae, C. N., Kelley, W. M., Fugelsang, J. A., \& Heatherton, T. F. (2006). The good, the bad, and the ugly: An fMRI investigation of the functional anatomic correlates of stigma. Social Neuroscience, 1, 5-15.

Krochik, M., \& Jost, J. T. (2011). Ideological conflict and polarization: A social psychological perspective. In D. Bar-Tal (Ed.), Intergroup conflicts and their resolution: Social psychological perspective (pp. 145-174). New York, NY: Psychology Press.

Krosch, A. R., Berntsen, L., Amodio, D. M., Jost, J. T., \& Van Bavel, J. J. J. (2013a). On the ideology of hypodescent: Political conservatism predicts categorization of racially ambiguous faces as Black. Journal of Experimental Social Psychology, 49, 1196-1203.

Krosch, A. R., Jost, J. T., \& Van Bavel, J. J. (2013b). Political orientation and the neural representation of Blackness. Manuscript in preparation.

Kubota, J. T., Banaji, M. R., \& Phelps, E. A. (2012). The neuroscience of race. Nature Neuroscience, 15, 940-948.

Kunda, Z. (1990). The case for motivated reasoning. Psychological Bulletin, 108, 480-498.

Lammers, J., \& Proulx, T. (2013). Writing autobiographical narratives increases political conservatism. Journal of Experimental Social Psychology, 49, 684-691.

Lang, P. J., Bradley, M. M., \& Cuthbert, B. N. (1990). Emotion, attention, and the startle reflex. Psychological Review, 97, $377-395$.

LaPonce, J. A. (1981). Left and right: The topography of political perceptions. Toronto, Canada: Toronto University Press.

Lavine, H., Jost, J. T., \& Lodge, M. (in press). Political cognition and its normative implications for the democratic experiment: Theory, evidence, and controversy. In E. Borgida \& J. Bargh (Eds.), APA handbook of personality and social psychology (Vol. 1). Washington, DC: APA.

Layman, G. C., \& Carsey, T. M. (2002). Party polarization and conflict extension in the American electorate. American Journal of Political Science, 46, 786-802.

LeDoux, J. (1996). Emotional networks and motor control: A fearful view. Progress in Brain Research, 107, 437-446.

LeDoux, J. (2000). Emotion circuits in the brain. Annual Review of Neuroscience, 23, 155-184.

Lieberman, M. D. (2000). Intuition: A social cognitive neuroscience approach. Psychological Bulletin, 126, $109-137$.

Lieberman, M. D., Hariri, A., Jarcho, J. M., Eisenberger, N. I., \& Bookheimer, S. Y. (2005). An fMRI investigation of race-related amygdala activity in African-American and Caucasian-American individuals. Nature Neuroscience, 8, $720-722$.

Lieberman, M. D., Schreiber, D., \& Ochsner, K. (2003). Is political cognition like riding a bicycle? How cognitive neuroscience can inform research on political thinking. Political Psychology, 24, 681-704.

Lipset, S. M. (1960). Political man: The social bases of politics. Garden City, NY: Doubleday.

Lipset, S. M., Lazarsfeld, P. F., Barton, A. H., \& Linz, J. (1954/1962). The psychology of voting: An analysis of political behavior. In G. Lindzey (Ed.), Handbook of social psychology (pp. 1124-1175). Reading, MA: Addison-Wesley.

Love, B. C., Medin, D. L., \& Gureckis, T. M. (2004). SUSTAIN: A network model of category learning. Psychological Review, 111, 309-332.

Macrae, C. N., \& Bodenhausen, G. V. (2000). Social cognition: Thinking categorically about others. Annual Review of Psychology, 51, 93-120.

Macrae, C. N., Bodenhausen, G. V., Schloerscheidt, A. M., \& Milne, A. B. (1999). Tales of the unexpected: Executive function and person perception. Journal of Personality and Social Psychology, 76, 200-213.

Macrae, C. N., Moran, J. M., Heatherton, T. F., Banfield, J. F., \& Kelley, W. M. (2004). Medial prefrontal activity predicts memory for self. Cerebral Cortex, 14, 647-654.

Malpass, R. S., \& Kravitz, J. (1969). Recognition for faces of own and other race. Journal of Personality and Social Psychology, 13, 330-334. 
Marcus, G. (2003). The psychology of emotion and politics. In D. O. Sears, L. Huddy, \& R. Jervis (Eds.), The Oxford handbook of political psychology (pp. 182-221). New York, NY: Oxford University Press.

Martin, A. (2007). The representation of object concepts in the brain. Annual Review of Psychology, 58, $25-45$.

Matthews, M., Levin, S., \& Sidanius, J. (2009). A longitudinal test of the model of political conservatism as motivated social cognition. Political Psychology, 30, 921-936.

McClosky, H. (1958). Conservatism and personality. American Political Science Review, 52, $27-45$.

McClosky, H., \& Zaller, J. (1984). The American ethos: Public attitudes toward capitalism and democracy. Cambridge, MA: Harvard University Press.

McGuire, W. J. (1985). Attitudes and attitude change. In G. Lindzey \& E. Aronson (Eds.), Handbook of social psychology (3rd ed., Vol. 2, pp. 233-346). New York, NY: Random House.

McGuire, W. J. (1993). The poly-psy relationship: Three phases of a long affair. In S. Iyengar \& W. J. McGuire (Eds.), Explorations in political psychology (pp. 9-35). Durham, NC: Duke University Press.

McLean, S. P., Garza, J. P., Wiebe, S. A., Dodd, M. D., Smith, K. B., Hibbing, J. R., \& Espy, K. A. (2013). Applying the flanker task to political psychology: A research note. Political Psychology. doi:10.1111/pops.12056

McManus, I. C. (2002). Right hand, left hand: The origins of asymmetry in brains, bodies, atoms and cultures. Cambridge, MA: Harvard University Press.

Mechelli, A., Crinion, J. T., Noppeney, U., O’Doherty, J., Ashburner, J., Frackowiak, R. S., \& Price, C. J. (2004). Structural plasticity in the bilingual brain. Nature, $431,757$.

Mendelberg, T. (2001). The race card: Campaign strategy, implicit messages, and the norm of equality. Princeton, NJ: Princeton University Press.

Mendoza, S. A., Gollwitzer, P. M., \& Amodio, D. M. (2010). Reducing the expression of implicit stereotypes: Reflexive control through implementation intentions. Personality and Social Psychology Bulletin, 36, 512-523.

Miller, E. K., \& Cohen, J. D. (2001). An integrative theory of prefrontal cortex function. Annual Review of Neuroscience, 24, 167-202.

Mitchell, J. P., Ames, D. L., Jenkins, A. C., \& Banaji, M. R. (2009). Neural correlates of stereotype application. Journal of Cognitive Neuroscience, 21, 594-604.

Mitchell, J. P., Heatherton, T. F., \& Macrae, C. N. (2002). Distinct neural systems subserve person and object knowledge. Proceedings of the National Academy of Sciences, 99, 15238-15243.

Mitchell, J. P., Macrae, C. N., \& Banaji, M. R. (2006). Dissociable medial prefrontal contributions to judgments of similar and dissimilar others. Neuron, 50, 655-663.

Mitchell, T. M., Shinkareva, S., Carlson, A., Chang, K. M., Malave, V. L., Mason, R. A., \& Just, M. A. (2008). Predicting human brain activity associated with the meanings of nouns. Science, 320, 1191-1195.

Mondak, J. J. (2010). Personality and the foundations of political behavior. New York, NY: Cambridge University Press.

Monteith, M. J., Ashburn-Nardo, L., Voils, C. I., \& Czopp, A. M. (2002). Putting the brakes on prejudice: On the development and operation of cues for control. Journal of Personality and Social Psychology, 83, 1029-1050.

Morris, J. P., Squires, N. K., Taber, C. S., \& Lodge, M. (2003). Activation of political attitudes: A psychophysiological examination of the hot cognition hypothesis. Political Psychology, 24, 727-745.

Nail, P. R., \& McGregor, I. (2009). Conservative shift among liberals and conservatives following 9/11/01. Social Justice Research, 22, 231-240.

Nail, P. R., McGregor, I., Drinkwater, A. E., Steele, G. M., \& Thompson, A. W. (2009). Threat causes liberals to think like conservatives. Journal of Experimental Social Psychology, 45, 901-907.

Nam, H. H., Jost, J. T., Campbell-Meiklejohn, D., \& Van Bavel, J. J. (2013, April). The neuroanatomical correlates of system justification. Poster presented at the $6^{\text {th }}$ Annual Meeting of the Social and Affective Neuroscience Society, San Francisco, CA.

Nam, H. H., Jost, J. T., \& Van Bavel, J. J. (2013). Not for all the tea in China! Political ideology and the avoidance of dissonance-arousing situations. PLoS ONE, 8(4): e59837. doi:10.1371/journal.pone.0059837

Napier, J. L. \& Jost, J. T. (2008). Why are conservatives happier than liberals? Psychological Science, 19, 565-572.

Nature Editorial. (2007). Mind games: how not to mix politics and science. Nature, 450, 457.

Newman-Norlund, R., Burch, J., \& Becofsky, K. (2013). Human Mirror Neuron System (hMNS) specific differences in resting-state functional connectivity in self-reported Democrats and Republicans: A pilot study. Journal of Behavioral and Brain Science, 3, 341-349. doi:10.4236/jbbs.2013).34034

Noël, A., \& Thérien, J. P. (2008). Left and right in global politics. New York, NY: Cambridge University Press.

Norman, K. A., Polyn, S. M., Detre, G. J., \& Haxby, J. V. (2006). Beyond mind-reading: Multi-variate pattern analysis of fMRI data. Trends in Cognitive Sciences, 10, 424-430. 
O'Doherty, J. P. (2004). Reward representations and reward-related learning in the human brain: Insights from neuroimaging. Current Opinion in Neurobiology, 14, 769-776.

Ofan, R. H., Rubin, N., \& Amodio, D. M. (2011). Seeing race: N170 responses to race and their relation to automatic racial attitudes and controlled processing. Journal of Cognitive Neuroscience, 23, 3152-3161.

Olson, L. R., \& Green, J. C. (2006). The religion gap. PS: Political Science, \& Politics, 39, 455-459.

Onraet, E., van Hiel, A., Dhont, K., \& Pattyn, S. (2013). Internal and external threat in relationship with right-wing attitudes. Journal of Personality, 81, 233-248.

Oxley, D. R., Smith, K. B., Alford, J. R., Hibbing, M. V., Miller, J. L., Scalora, M., Hatemi, P. K., \& Hibbing, J. R. (2008). Political attitudes vary with physiological traits. Science, 321, 1667-1670.

Pacilli, M. G., Taurino, A., Jost, J. T., \& Van der Toorn, J. (2011). System justification, rightwing conservatism, and internalized homophobia: Gay and lesbian attitudes toward same-sex parenting in Italy. Sex Roles: A Journal of Research, 65, 580-595.

Peery, D., \& Bodenhausen, G. V. (2008). Black + white = black: Hypodescent in reflexive categorization of racially ambiguous faces. Psychological Science, 19, 973-977.

Petty, R. E., \& Cacioppo, J. T. (1986). The elaboration likelihood model of persuasion. Advances in Experimental Social Psychology, 19, 123-205.

Phelps, E. A., O’Connor, K. J., Cunningham, W. A., Funayama, E. S., Gatenby, J. C., Gore, J. C., \& Banaji, M. R. (2000). Performance on indirect measures of race evaluation predicts amygdala activation. Journal of Cognitive Neuroscience, 12, 729-738.

Phelps, E. A., O'Connor, K. J., Gatenby, J. C., Grillon, C., Gore, J. C., \& Davis, M. (2001). Activation of the human amygdala to a cognitive representation of fear. Nature Neuroscience, 4, 437-441.

Piurko, Y., Schwartz, S. H., \& Davidov, E. (2011). Basic personal values and the meaning of left-right political orientations in 20 countries. Political Psychology, 32, 537-561.

Poldrack, R. A. (2006). Can cognitive processes be inferred from neuroimaging data? Trends in Cognitive Sciences, $10,59-63$.

Poldrack, R. A. (2008). The role of fMRI in cognitive neuroscience: Where do we stand? Current Opinion in Neurobiology, $18,223-227$.

Quadflieg, S., \& Macrae, C. N. (2011). Stereotypes and stereotyping: What's the brain got to do with it? European Review of Social Psychology, 22, 215-273.

Quadflieg, S., Turk, D. J., Waiter, G. D., Mitchell, J. P., Jenkins, A. C., \& Macrae, C. N. (2009). Exploring the neural correlates of social stereotyping. Journal of Cognitive Neuroscience, 21, 1560-1570.

Rankin, R. E., \& Campbell, D. T. (1955). Galvanic skin response to Negro and White experimenters. Journal of Abnormal and Social Psychology, 51, 30-33.

Raphael, D. D. (2001). Concepts of justice. New York, NY: Oxford University Press.

Ratner, K. G., \& Amodio, D. M. (2013). Seeing us vs. them: Minimal group effects on the neural encoding of faces. Journal of Experimental Social Psychology, 49, 298-301.

Ratner, K. G., Kaul, C., \& Van Bavel, J. J. (2012). Is race erased? Decoding race from patterns of neural activity when skin color is not diagnostic of group boundaries. Social Cognitive and Affective Neuroscience. doi:10.1093/scan/nss063

Regehr, G., \& Brooks, L. R. (1995). Category organization in free classification: The organizing effect of an array of stimuli. Journal of Experimental Psychology: Learning, Memory, and Cognition, 21, 347-363.

Rentfrow, P. J., Jost, J. T., Gosling, S. D., \& Potter, J. (2009). Statewide differences in personality predict voting patterns in 1996-2004 U.S. presidential elections. In J. T. Jost, A. C. Kay, \& H. Thorisdottir (Eds.), Social and psychological bases of ideology and system justification (pp. 314-347). New York, NY: Oxford University Press.

Richeson, J. A., Baird, A. A., Gordon, H. L., Heatherton, T. F., Wyland, C. L., Trawalter, S., \& Shelton, J. N. (2003). An fMRI investigation of the impact of interracial contact on executive function. Nature Neuroscience, 6, 1323-1328.

Rock, M., \& Janoff-Bulman, R. (2010). Where do we draw our lines? Politics, rigidity, and the role of self-regulation. Social Psychological and Personality Science, 1, 26-33.

Rokeach, M. (1960). The open and closed mind: Investigations into the nature of belief systems and personality systems. New York, NY: Basic Books.

Ronquillo J., Denson T. F., Lickel B., Lu Z.-L., Nandy A., \& Maddox K. B. (2007). The effects of skin tone on race-related amygdala activity: An fMRI investigation. Social Cognitive and Affective Neuroscience, 2, 39-44.

Rule, N. O., Freeman, J. B., Moran, J. M., Gabrieli, J. D. E., Adams, R. B., Jr., \& Ambady, N. (2010). Voting behavior is reflected in amygdala response across cultures. Social Cognitive and Affective Neuroscience, 5, 349-355.

Rutjens, B. T., \& Loseman, A. (2010). The society-supporting self: System justification and cultural worldview defense as different forms of self-regulation. Group Processes and Intergroup Relations, 13, 241-250.

Samson, D., Apperly, I. A., Chiavarino, C., \& Humphreys, G. W. (2004). Left temporoparietal junction is necessary for representing someone else's belief. Nature Neuroscience, 7, 499-500. 
Sargent, M. (2004). Less thought, more punishment: Need for cognition predicts support for punitive responses to crime. Personality and Social Psychology Bulletin, 30, 1485-1493.

Saucier, G. (2000). Isms and the structure of social attitudes. Journal of Personality and Social Psychology, 78, 366-385.

Saxe, R., \& Wexler, A. (2005). Making sense of another mind: the role of the right temporo-parietal junction. Neuropsychologia, 43, 1391-1399.

Schiller, D., Monfils, M.-H., Raio, C. M., Johnson, D. C., LeDoux, J. E., \& Phelps, E. A. (2009). Preventing the return of fear in humans using reconsolidation update mechanisms. Nature, 463, 49-53.

Schlenker, B. R., Chambers, J. R., \& Le, B. M. (2012). Conservatives are happier than liberals, but why? Political ideology, personality, and life satisfaction. Journal of Research in Personality, 46, 127-146.

Schreiber, D., Fonzo, G., Simmons, A. N., Dawes, C. T., Flagan, T., Fowler, J. H., \& Paulus, M. P. (2013). Red brain, blue brain: Evaluative processes differ in Democrats and Republicans. PLoS ONE, 8(2): e52970. doi:10.1371/ journal.pone. 0052970

Sears, D. O., \& Freedman, J. L. (1967). Selective exposure to information: A critical review. Public Opinion Quarterly, 31, 194-213.

Sears, D. O., Huddy, L., \& Jervis, R. (Eds.), (2003). Oxford handbook of political psychology. New York, NY: Oxford University Press.

Sears, D. O., Sidanius, J., \& Bobo, L. (Eds.), (2000). Racialized politics: The debate about racism in America. Chicago, IL: University of Chicago Press.

Seeley, W. W., Menon, V., Schatzberg, A. F., Keller, J., Glover, G. H., Kenna, H., Reiss, A. L., \& Greicius, M. D. (2007). Dissociable intrinsic connectivity networks for salience processing and executive control. Journal of Neuroscience, 27 , 2349-2356.

Shafer, B. E., \& Claggett, W. J. (1995). The two majorities: The issue context of modern American politics. Baltimore, MD: The John Hopkins University Press.

Shepard, R. N., Hovland, C. I., \& Jenkins, H. M. (1961). Learning and memorization of classifications. Psychological Monographs: General and Applied, 75, 1-42.

Sherman, J. W., Lee, A. Y., Bessenoff, G. R., \& Frost, L. A. (1998). Stereotype efficiency reconsidered: Encoding flexibility under cognitive load. Journal of Personality and Social Psychology, 75, 589-606.

Shook, N. J., \& Fazio, R. H. (2009). Political ideology, exploration of novel stimuli, and attitude formation. Journal of Experimental Social Psychology, 45, 995-998.

Sidanius, J. (1985). Cognitive functioning and socio-political ideology revisited. Political Psychology, 6, 637-661.

Smith, E. R., \& DeCoster, J. (2000). Dual process models in social and cognitive psychology: Conceptual integration and links to underlying memory systems. Personality and Social Psychology Review, 4, 108-131.

Smith, K. B., Oxley, D. R., Hibbing, M. V., Alford, J. R., \& Hibbing, J. R. (2011a). Disgust sensitivity and the neurophysiology of left-right political orientations. PLoS ONE, 6(10): e25552. doi:10.1371/journal.pone.0025552

Smith, K. B., Oxley, D. R., Hibbing, M. V., Alford, J. R., \& Hibbing, J. R. (2011b). Linking genetics and political attitudes: Reconceptualizing political ideology. Political Psychology, 32, 369-397.

Spreng, R. N., Mar, R. A., \& Kim, A. S. N. (2009). The common neural basis of autobiographical memory, prospection, navigation, theory of mind, and the default mode: A quantitative meta-analysis. Journal of Cognitive Neuroscience, 21, 489-510.

Taber, C. S., \& Lodge, M. (2006). Motivated skepticism in the evaluation of political beliefs. American Journal of Political Science, 50, 755-769.

Taber, C. S., \& Young, E. (2013). Political information processing. In L. Huddy, D. O. Sears, \& J. Levy (Eds.), The Oxford handbook of political psychology (pp. 525-558). New York, NY: Oxford University Press.

Tajfel, H., Billig, M. G., Bundy, R. P., \& Flament, C. (1971). Social categorization and intergroup behavior. European Journal of Social Psychology, 1, 149-178.

Tarnopolsky, C. H. (2010). Prudes, perverts, and tyrants: Plato's Gorgias and the politics of shame. Princeton, NJ: Princeton University Press.

Tedin, K. L. (1987). Political ideology and the vote. Research in Micropolitics, 2, 63-94.

Terbeck, S., Kahane, G., McTavish, S., Savulscu, J., Cowen, P. J., \& Hewstone, M. (2012). Propranolol reduces implicit negative racial bias. Psychopharmacology, 222, 419-424.

Tetlock, P. E. (1983). Cognitive style and political ideology. Journal of Personality and Social Psychology, 45, 118-126.

Tetlock, P. E. (2007). Psychology and politics: The challenges of integrating levels of analysis in social science. In E. T. Higgins \& A. Kruglanski (Eds.), Social psychology: Handbook of basic principles (pp. 888-912). New York, NY: Guilford.

Theodoridis, A. G., \& Nelson, A. J. (2012). Of BOLD claims and excessive fears: A call for caution and patience regarding political neuroscience. Political Psychology, 33, 27-43. 
Thomas, C., \& Baker, C. I. (2012). Teaching an adult brain new tricks: A critical review of evidence for training-dependent structural plasticity in humans. Neuroimage, 73, 225-236.

Thorisdottir, H., \& Jost, J. T. (2011). Motivated closed-mindedness mediates the effect of threat on political conservatism. Political Psychology, 32, 785-811.

Tomkins, S. (1963). Left and right: A basic dimension of ideology and personality. In R. W. White (Ed.), The study of lives (pp. 388-411). Chicago, IL: Atherton.

Tusche, A., Kahnt, T., Wisniewski, D., \& Haynes, J. (2013). Automatic processing of political preferences in the human brain. Neuroimage, 72, 174-182.

Tybur, J. M., Merriman, L. A., Hooper, A. E. C., McDonald, M. M., \& Navarrete, C. D. (2010). Extending the behavioral immune system to political psychology: Are political conservatism and disgust sensitivity related? Evolutionary Psychology, 8, 599-616.

Ullrich, J., \& Cohrs, J. C. (2007). Terrorism salience increases system justification: Experimental evidence. Social Justice Research, 20, 117-139.

Valentino, N. A., Hutchings, V. L., \& White, I. K. (2002). Cues that matter: How political ads prime racial attitudes during campaigns. American Political Science Review, 96, 75-90.

Van Bavel, J. J., \& Cunningham, W. A. (2009). Self-categorization with a novel mixed-race group moderates automatic social and racial biases. Personality and Social Psychology Bulletin, 35, 321-335.

Van Bavel, J. J., \& Cunningham, W. A. (2011). A social neuroscience approach to self and social categorisation: A new look at an old issue. European Review of Social Psychology, 21, 237-284.

Van Bavel, J. J., \& Cunningham, W. A. (2012). A social identity approach to person memory: Group membership, collective identification, and social role shape attention and memory. Personality and Social Psychology Bulletin, 38, $1566-1578$.

Van Bavel, J. J., Packer, D. J., \& Cunningham, W. A. (2008). The neural substrates of in-group bias: A functional magnetic resonance imaging investigation. Psychological Science, 19, 1131-1139.

Van Bavel, J. J., Packer, D. J., \& Cunningham, W. A. (2011). Modulation of the fusiform face area following minimal exposure to motivationally relevant faces: Evidence of in-group enhancement (not out-group disregard). Journal of Cognitive Neuroscience, 23, 3343-3354.

van der Plas, E. A. A., Boes, A. D., Wemmie, J. A., Tranel, D., \& Nopoulos, P. (2010). Amygdala volume correlates positively with fearfulness in normal healthy girls. Social Cognitive and Affective Neuroscience, 5, 424-431.

van Hiel, A., Onraet, E., \& De Pauw, S. (2010). The relationship between socio-cultural attitudes and behavioral measures of cognitive style: A meta-analytic integration of studies. Journal of Personality, 78, 1765-1800.

van Hiel, A., Pandelaere, M., \& Duriez, B. (2004). The impact of need for closure on conservative beliefs and racism: Differential mediation by authoritarian submission and authoritarian dominance. Personality and Social Psychology Bulletin, 30, 824-837.

van Leeuwen, F., \& Park, J. H. (2009). Perceptions of social dangers, moral foundations, and political orientation. Personality and Individual Differences, 47, 169-173.

Vecchione, M., Caprara, G., Dentale, F., \& Schwartz, S. H. (2013). Voting and values: Reciprocal effects over time. Political Psychology, 34, 465-485.

Verhulst, B., Eaves, L. J., \& Hatemi, P. K. (2012). Correlation not causation: The relationship between personality traits and political ideologies. American Journal of Political Science, 56, 34-51.

Vigil, J. M. (2010). Political leanings vary with facial expression processing and psychosocial functioning. Group Processes \& Intergroup Relations, 13, 547-558.

Vogt, B. A. (2005). Pain and emotion interactions in subregions of the cingulate gyrus. Nature Reviews Neuroscience, 6 , 533-544.

Weber, C., \& Federico, C. (2007). Interpersonal attachment and patterns of ideological belief. Political Psychology, 28, 389-411.

Weissflog, M. J., Choma, B. L., Dywan, J., van Noordt, S. J. R., \& Segalowitz, S. J. (2013). The political (and physiological) divide: Political orientation, performance monitoring, and the anterior cingulate response. Social Neuroscience, 8 , 434-447.

Westen, D., Blagov, P. S., Harenski, K., Kilts, C., \& Hamann, S. (2006). Neural bases of motivated reasoning: An fMRI study of emotional constraints on partisan political judgment in the 2004 U.S. presidential election. Journal of Cognitive Neuroscience, 18, 1947-1958.

Whalen, P. J. (1998). Fear, vigilance, and ambiguity: Initial neuroimaging studies of the human amygdala. Current Directions in Psychological Science, 7, 177-188.

Whalen, P. J. (2007). The uncertainty of it all. Trends in Cognitive Sciences, 11, 499-500.

Wheeler, M. E., \& Fiske, S. T. (2005). Controlling racial prejudice: Social-cognitive goals affect amygdala and stereotype activation. Psychological Science, 16, 56-63. 
Wicker, B., Keysers, C., Plailly, J., Royet, J. Gallese, V., \& Rizzolatti, G. (2003). Both of us disgusted in my insula: The common neural basis of seeing and feeling disgust. Neuron, 40, 655-664.

Wilson, E. O. (1998). Consilience: The unity of knowledge. New York, NY: Vintage Books.

Wilson, G. D. (Ed.). (1973). The psychology of conservatism. London, UK: Academic Press.

Woollett, K., \& Maguire, E. A. (2011). Acquiring the knowledge of London's layout drives structural brain changes. Current Biology, 21, 2109-2114.

Zamboni, G., Gozzi, M., Krueger, F., Duhamel, J., Sirigu, A., \& Grafman, J. (2009). Individualism, conservatism, and radicalism as criteria for processing political beliefs: A parametric fMRI study. Social Neuroscience, 4, 367-383. 